Article

\title{
Early Developmental Zebrafish Embryo Extract to Modulate Senescence in Multisource Human Mesenchymal Stem Cells
}

\author{
Federica Facchin $1,2,+\left(\mathbb{D}\right.$, Francesco Alviano ${ }^{1,+}+\mathbb{D}$, Silvia Canaider ${ }^{1,2, *(\mathbb{D})}$, Eva Bianconi ${ }^{1,2}$, \\ Martina Rossi ${ }^{1}$, Laura Bonsi ${ }^{1}$, Raffaella Casadei ${ }^{3}{ }^{(-)}$, Pier Mario Biava ${ }^{4}$ and Carlo Ventura ${ }^{1,2}$ \\ 1 Department of Experimental, Diagnostic and Specialty Medicine (DIMES), University of Bologna, \\ Via Massarenti 9, 40138 Bologna, Italy; federica.facchin2@unibo.it (F.F.); francesco.alviano@unibo.it (F.A.); \\ eva.bianconi2@unibo.it (E.B.); martina.rossi12@unibo.it (M.R.); laura.bonsi@unibo.it (L.B.); \\ carlo.ventura@unibo.it (C.V.) \\ 2 National Laboratory of Molecular Biology and Stem Cell Bioengineering of the National Institute of \\ Biostructures and Biosystems (NIBB)-Eldor Lab, at the Innovation Accelerator, CNR, Via Piero Gobetti 101, \\ 40129 Bologna, Italy \\ 3 Department for Life Quality Studies (QuVi), University of Bologna, Corso D’Augusto 237, \\ 47921 Rimini, Italy; r.casadei@unibo.it \\ 4 Scientific Institute of Research and Care Multimedica, Via Milanese 300, 20099 Sesto San Giovanni (Milano), \\ Italy; biava@tiscali.it \\ * Correspondence: silvia.canaider@unibo.it; Tel.: +39-051-2094104 \\ + These authors contributed equally to this work.
}

Received: 16 April 2019; Accepted: 25 May 2019; Published: 29 May 2019

check for updates

\begin{abstract}
Stem cells undergo senescence both in vivo, contributing to the progressive decline in self-healing mechanisms, and in vitro during prolonged expansion. Here, we show that an early developmental zebrafish embryo extract (ZF1) could act as a modulator of senescence in human mesenchymal stem cells (hMSCs) isolated from both adult tissues, including adipose tissue (hASCs), bone marrow (hBM-MSCs), dental pulp (hDP-MSCs), and a perinatal tissue such as the Wharton's Jelly (hWJ-MSCs). In all the investigated hMSCs, ZF1 decreased senescence-associated $\beta$-galactosidase (SA $\beta$-gal) activity and enhanced the transcription of TERT, encoding the catalytic telomerase core. In addition, it was associated, only in hASCs, with a transcriptional induction of BMI1, a pleiotropic repressor of senescence. In hBM-MSCs, hDP-MSCs, and hWJ-MSCs, TERT over-expression was concomitant with a down-regulation of two repressors of TERT, TP53 (p53), and CDKN1A (p21). Furthermore, ZF1 increased the natural ability of hASCs to perform adipogenesis. These results indicate the chance of using ZF1 to modulate stem cell senescence in a source-related manner, to be potentially used as a tool to affect stem cell senescence in vitro. In addition, its anti-senescence action could also set the basis for future in vivo approaches promoting tissue rejuvenation bypassing stem cell transplantation.
\end{abstract}

Keywords: stem cells; senescence; zebrafish embryo extract; senescence-associated $\beta$-galactosidase activity; adipogenesis; TERT; BMI1; $553 ; p 21 ; p 16$

\section{Introduction}

The human body continuously relies upon its own tissue-resident stem cells to repair adult tissues and organs, and to oppose senescence-related processes [1-6]. Human mesenchymal stem cells (hMSCs) exhibit self-renewal, multilineage differentiation and can be isolated and expanded in vitro from virtually all organs, even if bone marrow and subcutaneous fat are the elected sources [7]. 
Furthermore, hMSCs can be isolated not only from adult tissues but also from several fetal and perinatal sources [8].

As a result, in the last decade several attempts have been made to unfold hMSC features into regenerative medicine approaches for the treatment of a variety of tissue injuries and degenerative disorders [9-15]. Within this context, the use of synthetic and natural molecules, as well as electromagnetic fields and mechanical vibrations, can largely contribute to the development of strategies that may counteract stem cell senescence allowing the preservation of tissue homeostasis and our innate self-healing potential [16].

In particular, in neurodegenerative diseases, strategies that prevent telomere loss or increase telomere length in MSCs, as well as the use of neuropeptides that elicit the regulation of the Wnt/ $\beta$-catenin signaling pathway (involved in the shift of MSCs towards a senescent phenotype), may prevent the symptoms of neurodegenerative disorders and improve the results of MSCs-based therapy [17]. At the same time, therapeutic approaches of osteoarthritis are based on strategies able to stimulate MSCs through telomerase activators, mechanical strain, and epigenetic regulation in order to maintain their chondrogenic differentiation potential and to counteract homeostasis alterations occurring in cell in vitro cultivation and expansion [18].

Another possible and useful way to resist stem cell senescence is mimicking organisms that have developed a robust ability to regenerate tissues. Zebrafish (Danio rerio), for example, is widely used as an animal model to study regeneration and organogenesis, given its ability to regenerate organs, such as the heart or the central nervous system, at a noticeable higher efficacy than in humans [19-23]. Despite the evolutionary distance between humans and zebrafish, hMSCs can still perceive ancestral microenvironmental cues from this species [24] and several scientific researches in comparative biology revealed interesting conserved evolutionary patterns in tissue regeneration.

Previously, we described a putative anti-senescence action of a zebrafish extract (ZF1) which was obtained from embryos at an early stage of development (50\% epiboly) in hMSCs that were isolated from the adipose tissue (human adipose tissue-derived stem cells, hASCs) and cultured from the third to the 5th passage, in order to provide a preliminary investigation of its effects on cell viability, stemness, and senescence regulatory patterning [25]. In particular, ZF1 which was given at a concentration of $10 \mu \mathrm{g} / \mathrm{mL}$ for $72 \mathrm{~h}$ did not influence cell viability or apoptosis, while it enhanced the transcription of the telomerase reverse transcriptase (TERT), BMI1 proto-oncogene, polycomb ring finger (BMI1), and the stemness POU domain class 5 homeobox 1 (POU5F1) (alias Oct-4), Sox-2, and v-myc avian myelocytomatosis viral oncogene homolog $(c-M y c)$ genes [25].

Recently, we investigated the role of ZF1 at the same dose and for the same exposure time on hASCs at four different, considerably more prolonged, subculture stages (5th, 10th, 15th and 20th) in order to assess additional biological responses to the treatment with ZF1. Our results showed that ZF1 is a feasible tool to modulate and reverse hASC senescence in long-term culturing conditions [26].

Since the zebrafish is considered one of the most popular vertebrate models in developmental biology and biomedical research, several transcriptomic and proteomic analyses have been increasingly used for profiling important molecules of zebrafish at different developmental stages or in specific organs/tissues or experimental conditions [27-40].

Only one study [36], among all considered, reported the transcriptome at the specific developmental stage of our interest ( $50 \%$ epiboly) and a second reported a list of proteins isolated from the ZF1 extract [41].

In the present study, we first explored the anti-senescence role of ZF1 in hASCs treated for $72 \mathrm{~h}$ with $\mathrm{ZF} 1$ at five different concentrations $(0.01,10,20,40$, and $100 \mu \mathrm{g} / \mathrm{mL})$, in order to evaluate the eligible ZF1 dose to use in the present work.

Then, we investigated whether the anti-senescence action of ZF1 at a defined concentration can be considered a general feature applicable to various types of hMSCs isolated from adult and perinatal tissues. 
Therefore, we investigated cell proliferation, senescence-associated $\beta$-galactosidase (SA $\beta$-gal) activity, adipogenic ability, gene transcription of TERT, encoding the catalytic core of telomerase, BMI1, a transcriptional regulator acting as a major repressor of senescence, tumor protein $p 53$ (TP53, alias $p 53$ ), cyclin dependent kinase inhibitor $1 A$ (CDKN1A, alias p21), cyclin dependent kinase inhibitor $2 A$ (CDKN2A, alias $p 16$ ), p21 protein expression in ZF1-treated hMSCs from adipose tissue (hASCs), bone marrow (hBM-MSCs), dental pulp (hDP-MSCs), and Wharton's Jelly (hWJ-MSCs).

\section{Results}

\section{1. hMSC Isolation and Phenotype Characterization}

Cells were isolated from different sources, as described in the Material and Methods section, and were selected for their ability to adhere to plastic surfaces. After two to three weeks of in vitro culture, cell populations showed the typical fibroblast-like morphology (Figure 1) and displayed an immune phenotype consistent with multipotent mesenchymal stem cells. In fact, cell populations were positive for markers CD29, CD44, CD73, CD105, and CD166; and negative for CD14, CD34, and CD45. These results were previously described in detail $[42,43]$.

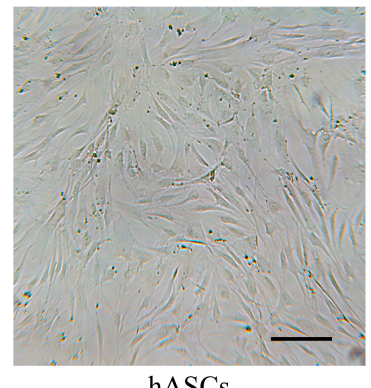

hASCs

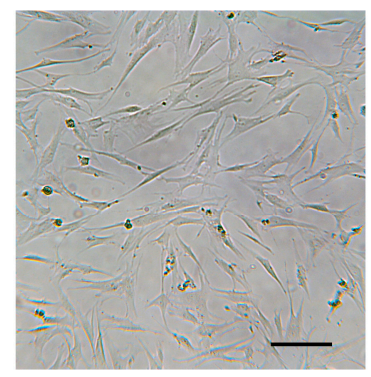

hBM-MSCs

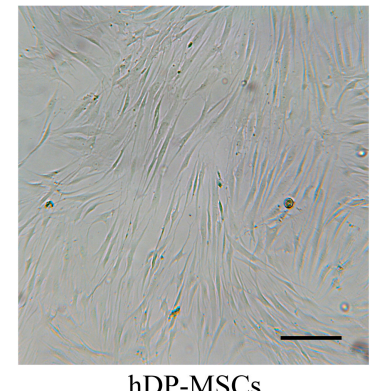

hDP-MSCs

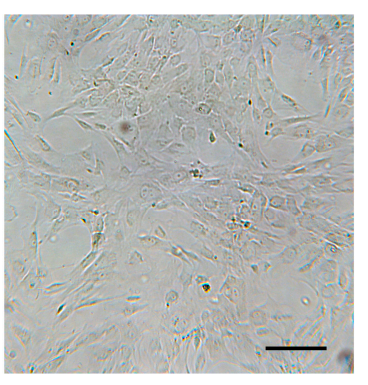

hWJ-MSCs

Figure 1. Representative images of hMSCs (culture passages 5th-7th) isolated from human adipose tissue (hASCs), dental pulp (hDP-MSCs), bone marrow (hBM-MSCs), and Wharton's Jelly (hWJ-MSCs). Cells were analyzed for morphology under optical microscopy $(40 \times$ magnification and bright field illumination). Scale bar corresponds to $200 \mu \mathrm{m}$.

\subsection{Evaluation of Different ZF1 Concentrations Cytotoxicity in hASCS}

A dose-response morphological analysis of the effects elicited by ZF1 on hASCs showed that the higher concentrations ( 40 and $100 \mu \mathrm{g} / \mathrm{mL}$ ) which were investigated modified cell morphology and induced high mortality. This suggested a toxicity of the treatments, and consequently, lead to their exclusion from further experiments. In contrast, treatment with a solvent or with ZF1 at 0.01, 10, and $20 \mu \mathrm{g} / \mathrm{mL}$ did not alter the cellular morphology, as compared with control cells from the same culture passages (5th-7th) (Figure 2). 

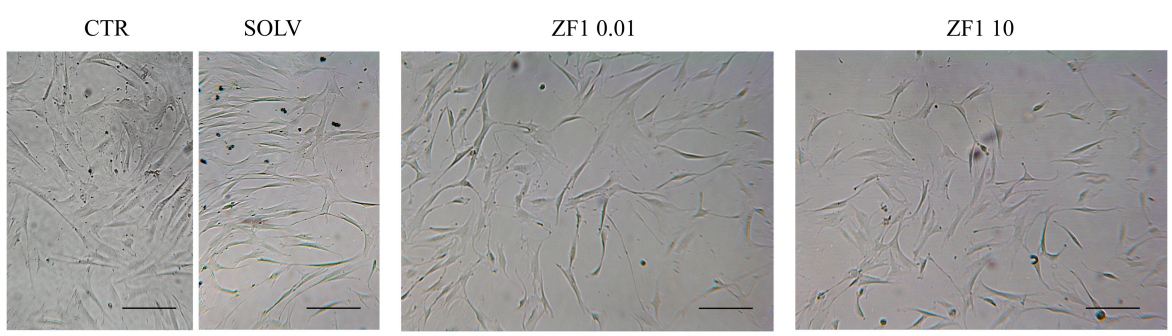

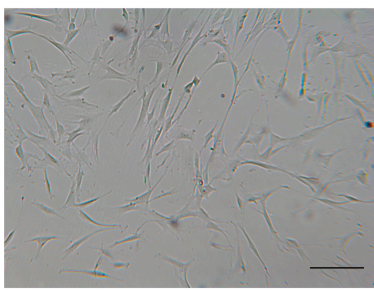

ZF1 20

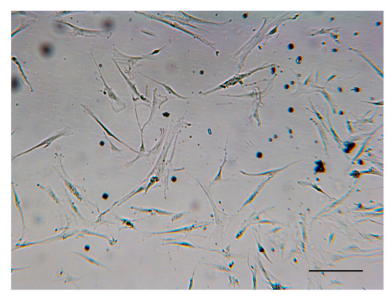

ZF1 40

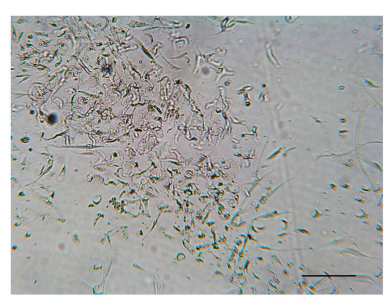

ZF1 100

Figure 2. Representative images of hASCs treated with ZF1 at different concentrations $(0.01,10,20$, 40 , and $100 \mu \mathrm{g} / \mathrm{mL}$ ) or with a solvent (SOLV) or untreated (CTR). Cytotoxicity was evaluated with a morphological analysis. Images were obtained with an optical microscopy $(40 \times$ magnification and bright field illumination). Scale bar corresponds to $200 \mu \mathrm{m}$.

\subsection{ZF1 Does Not Affect Proliferation in hASCs}

The preliminary in vitro toxicology resazurin-based assay performed on hASCs in technical quadruplicate showed a comparable proliferation rate in all the tested experimental conditions (control, solvent, and $\mathrm{ZF1}$ at $0.01,10$, and $20 \mu \mathrm{g} / \mathrm{mL}$ ), indicating that treatments had a nontoxic effect and that ZF1 did not affect hASC proliferation (Figure 3).

On the basis of these results, we decided to use a solvent as a control for subsequent experiments.

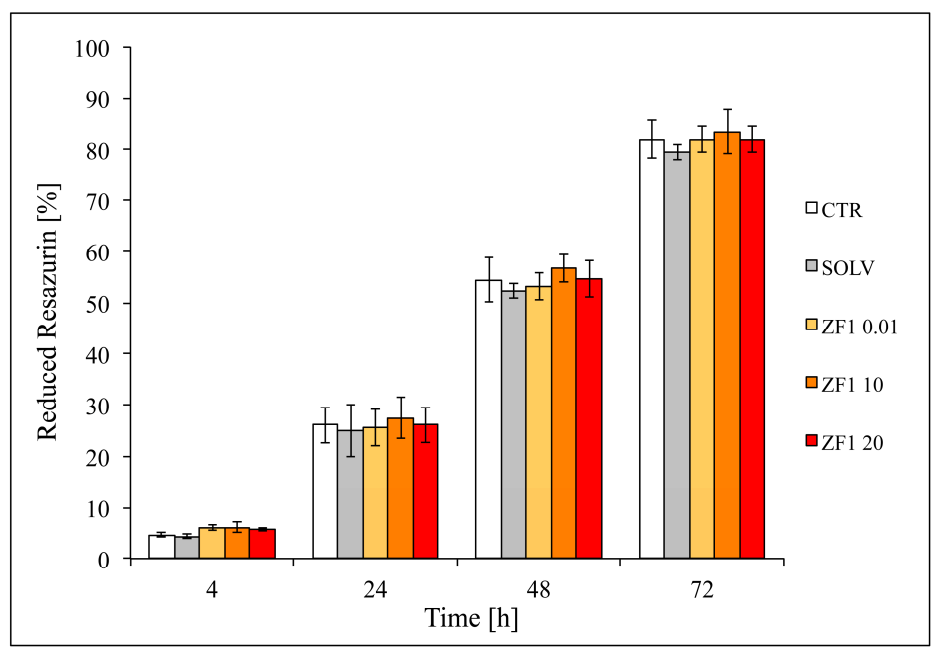

Figure 3. Effects of different concentrations of ZF1 on metabolic activity in hASCs. The percentage of resazurin reduction (as an indicator of cell proliferation) in hASCs treated with ZF1 $(0.01,10$, and $20 \mu \mathrm{g} / \mathrm{mL}$ ) or a solvent (SOLV) or untreated (CTR). An analysis was conducted at 4, 24, 48, and $72 \mathrm{~h}$ from the beginning of the treatment and an experiment was performed in technical quadruplicate. Statistical significance was evaluated using ANOVA followed by the Tukey HSD test. Data are expressed as mean \pm standard deviation (SD), $n=4$.

\subsection{ZF1 Decreases SA $\beta$-Gal Staining and Increases TERT Gene Expression in hASCS}

A dose-response analysis of the effects elicited by ZF1 on SA $\beta$-gal staining was set up in hASCs to identify the most effective concentration influencing the expression of this senescence marker. Cells 
(culture passages 5th-7th) were treated for $72 \mathrm{~h}$ with $\mathrm{ZF} 1$ at the final concentrations of $0.01,10$, and $20 \mu \mathrm{g} / \mathrm{mL}$. Although $0.01 \mu \mathrm{g} / \mathrm{mL}$ ZF1 was ineffective, both 10 and $20 \mu \mathrm{g} / \mathrm{mL}$ ZF1 significantly reduced the number of senescent hASCs positively blue stained for SA $\beta$-gal $(p<0.05)$ (Figure 4$)$.

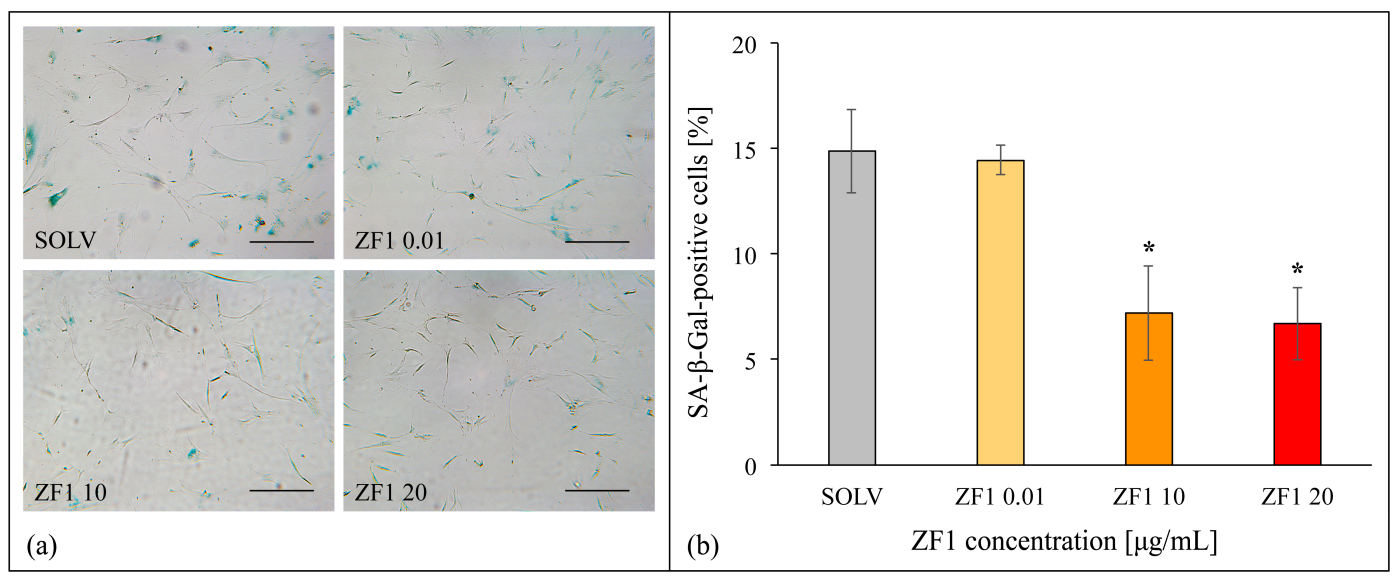

Figure 4. Effects of different concentrations of ZF1 on SA $\beta$-gal activity in hASCs. The hASCs (culture passages 5th-7th) were seeded in 6-well plates and were cultured in the presence of $0.01,10$, and $20 \mu \mathrm{g} / \mathrm{mL} \mathrm{ZF1}$, or a solvent as a control for $72 \mathrm{~h}$, then processed for SA $\beta$-gal assessment. (a) Images represent hASCs after SA $\beta$-gal staining. SA $\beta$-gal positive cells are blue. The scale bar corresponds to $200 \mu \mathrm{m}$; (b) Positive (blue) and negative (not colored) cells were counted in at least three random fields for each technical replicate under the microscope (200× magnification and bright field illumination). Data represent the percentage of SA $\beta$-gal positive cells calculated as the number of positive cells divided by the total number of counted cells multiplied by 100 (percentage of blue cells $\pm \mathrm{SD}, n=3$, statistical significance was calculated using the Student's $t$-test, $\left.{ }^{*} p<0.05\right)$.

Consistent with the experiments assessing the effect of ZF1 on SA $\beta$-gal activity, hASCs (isolated from one subject) and treated with $\mathrm{ZF} 1$ at $0.01 \mu \mathrm{g} / \mathrm{mL}$ concentration showed a gene expression value of the catalytic subunit of telomerase (TERT) similar to that of control cells (SOLV). In contrast, hASCs exposed to both $10 \mu \mathrm{g} / \mathrm{mL}$ and $20 \mu \mathrm{g} / \mathrm{mL}$ ZF1 resulted in a similar statistically significant increase in TERT transcription as compared with the control hASCs (SOLV) (Figure 5).

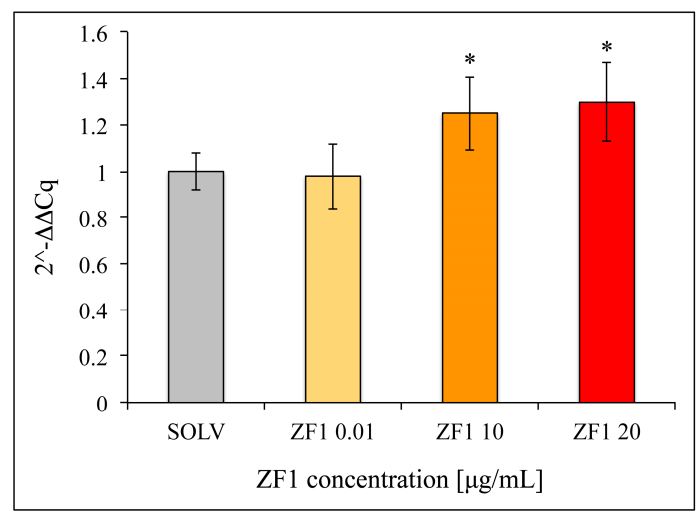

Figure 5. The effect of ZF1 treatment on TERT gene expression in hASCs. The hASCs (culture passages

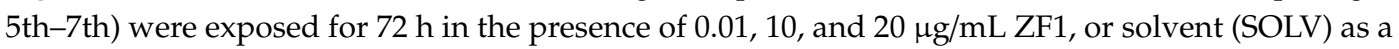
control. The expression value of the transcripts evaluated in solvent or ZF1-treated cells was normalized to the expression levels of three reference genes, HPRT1, GAPDH and TBP. The amount of the target mRNA in the ZF1 treated cells was plotted as the fold change over the expression in control cells. The experiment was performed in technical triplicate. Statistical significance was evaluated by using the CFX Manager Software version 3.1 (Bio-Rad Laboratories) and Student's t-test (mean \pm SD, $n=3$, $* p<0.05)$. 


\subsection{ZF1 Promotes Adipogenesis in hASCs}

To better investigate the effect of ZF1 on hASCs, adipogenic differentiation after $0.01,10$, and $20 \mu \mathrm{g} / \mathrm{mL}$ treatment was evaluated and quantified via Oil Red O staining, a neutral triglycerides and lipids dye. During differentiation, the hASCs produce multiple lipid-rich vacuoles in the cytoplasm, which increased in their size and number during the two weeks of induction, and they showed an intense red color if stained with Oil Red O (Figure 6a). The red staining quantification revealed that ZF1 enhanced hASC adipogenic commitment both when cells grew in a culture medium and when cells were induced. Moreover, the statistically significant effect was dose-dependent (Figure 6b).

Therefore, based on the above results obtained with hASCs, we decided to use ZF1 at $20 \mu \mathrm{g} / \mathrm{mL}$ in the following experiments performed on all the four selected hMSC types.

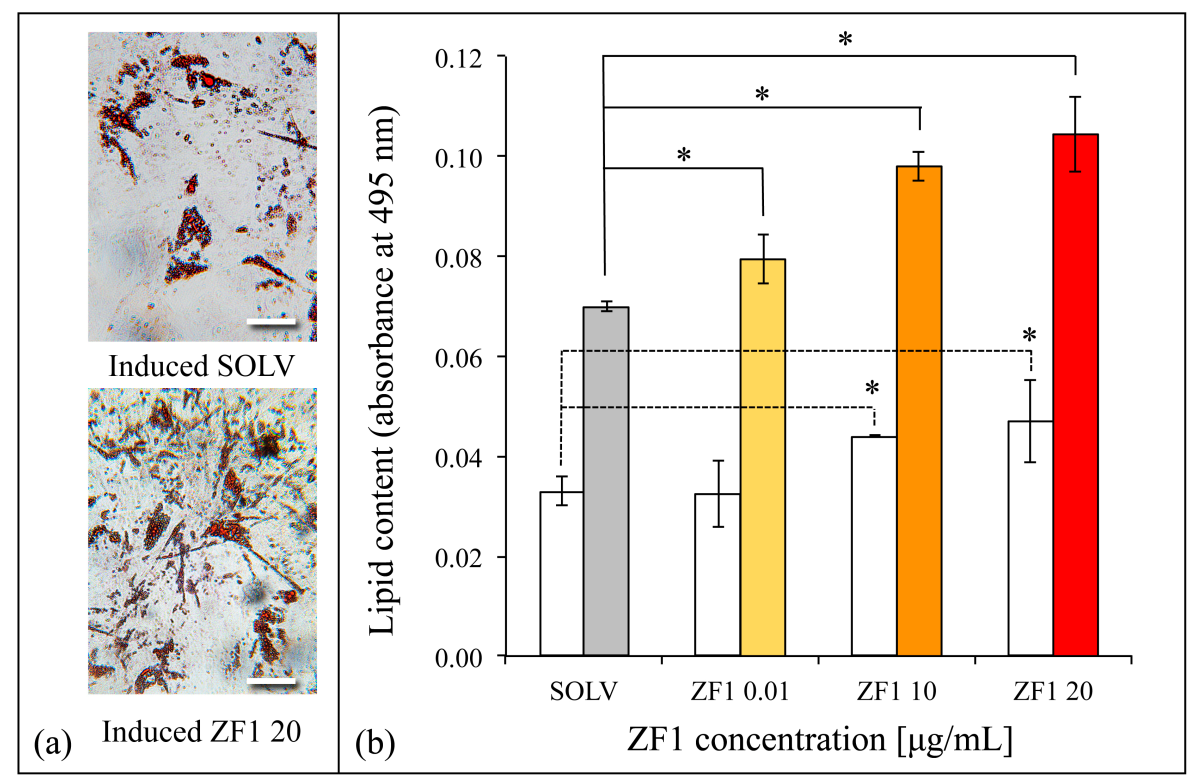

Figure 6. Effects of ZF1 treatment on adipogenic differentiation in hASCs at different concentrations. The hASCs (culture passages 5th-7th) were seeded in 24-well plates and were cultured in the presence of

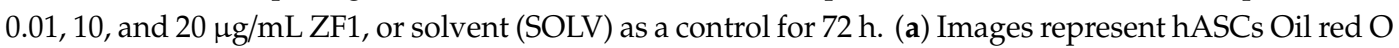
staining after treatment with solvent (above) or ZF1 $20 \mu \mathrm{g} / \mathrm{mL}$ (below) and adipogenic medium. Cells positive for adipogenesis showed red colored vacuoles in cytoplasm. Scale bar corresponds to $100 \mu \mathrm{m}$; (b) White histograms represent data derived from hASCs cultured in basal medium, while colored histograms represent those from hASCs treated with adipogenic medium. The lipid-rich vacuoles Oil Red O dye was extracted by wells and its absorbance was read at $495 \mathrm{~nm}$ with a spectrophotometer. Data are expressed as mean of lipid content at $495 \mathrm{~nm}$ absorbance \pm SD. Horizontal dashed or continuous black lines represent the significance of differences between data obtained from hASCs cultured in basal and from an adipogenic medium, respectively (statistical significance was calculated using the Student's $t$-test, $\left.{ }^{*} p<0.05, n=3\right)$.

\subsection{ZF1 and Modulation of Cell Proliferation in hMSCs Isolated from Four Different Sources}

The adult stem cells, hASCs, hDP-MSCs, and hBM-MSCs, and perinatal stem cells, hWJ-MSCs, (all at culture passages 5th-7th) were treated for $72 \mathrm{~h}$ with $20 \mu \mathrm{g} / \mathrm{mL}$ ZF1 or with its solvent as a control. As shown in Figure 7a, the percentage of reduction of resazurin (as an indicator of cell proliferation) did not change in the ZF1 treated hASCs as compared with solvent treated cells at any experimental time point, in accordance with our previous assay results reported above.

In contrast, in hBM-MSCs, hDP-MSCs, and hWJ-MSCs cell proliferation increased after ZF1 treatment, reaching statistical significance at different experimental points: at $72 \mathrm{~h}$ for all three cell types $(p<0.05)$ and also at $24 \mathrm{~h}$ and $48 \mathrm{~h}$ for hDP-MSCs and hWJ-MSCs (Figure 7b-d). 


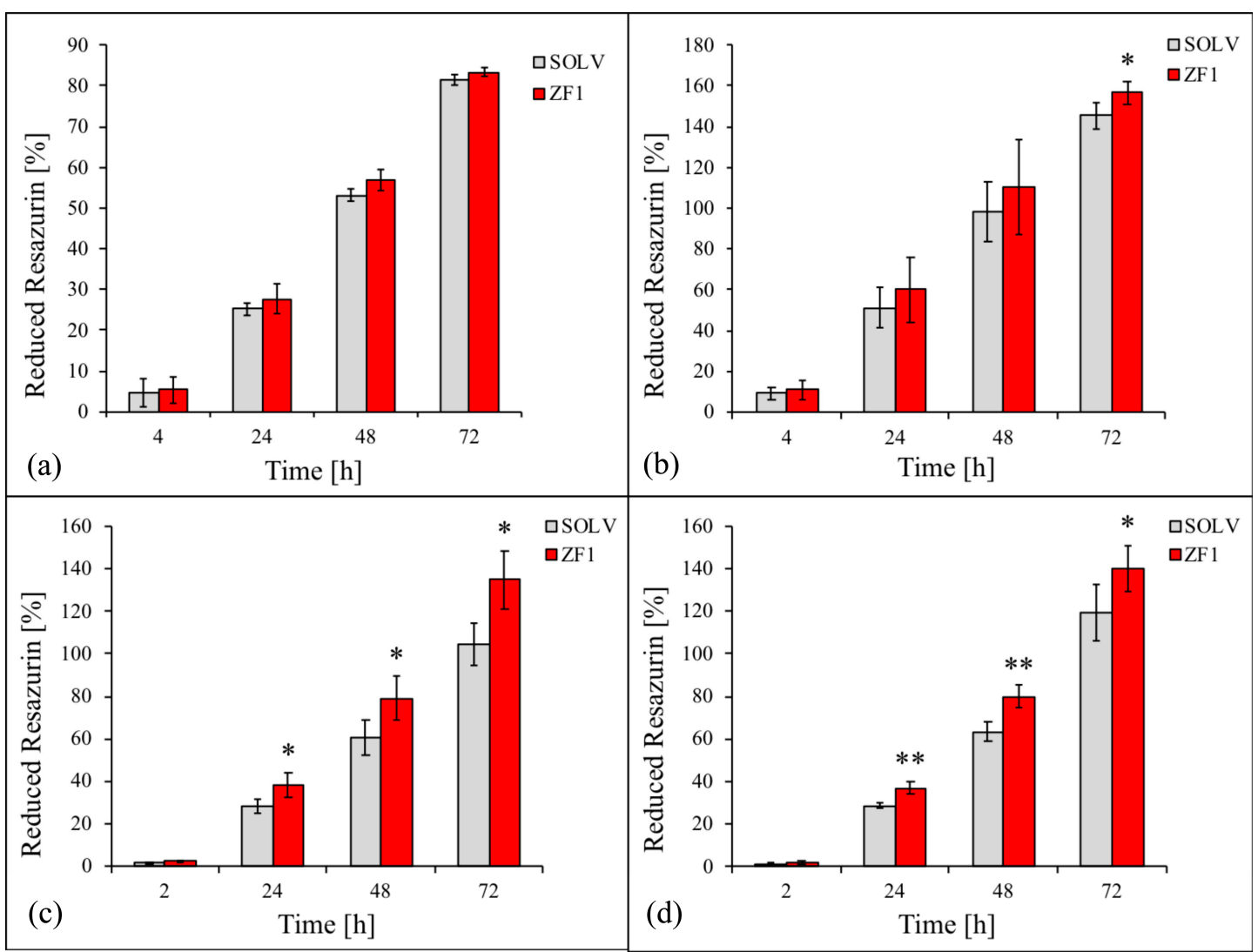

Figure 7. The effects of different concentrations of ZF1 on metabolic activity in hMSCs. The hASCs (a), hBM-MSCs (b), hDP-MSCs (c) and hWJ-MSCs (d), at passages 5th-7th, were exposed for $72 \mathrm{~h}$ in the

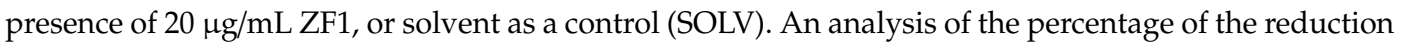
of resazurin (as an indicator of cell proliferation) was conducted at 4, 24, 48, and $72 \mathrm{~h}$ from the beginning of the treatment and data are expressed as mean $(n=3) \pm$ SD. Statistical significance was analyzed with ANOVA followed by the Tukey HSD test, ${ }^{*} p<0.05,{ }^{* *} p<0.01$.

\subsection{ZF1 Reduces SA $\beta$-Gal Staining in hMSCs Isolated from Four Different Sources}

All investigated hMSCs (culture passages 5th-7th) were treated for $72 \mathrm{~h}$ with $20 \mu \mathrm{g} / \mathrm{mL}$ ZF1 or with its solvent as a control and tested with the SA $\beta$-gal staining assay. As shown in Figure 8, the number of senescent stem cells expressing SA $\beta$-gal was remarkably reduced by the treatment, as compared with the control cells, in each investigated mesenchymal lineage $(n=3, p<0.01)$. The different distribution of SA $\beta$-gal positive cells among ZF1-exposed and untreated hMSCs of each source is also evident in Figure 9, showing the relevant decline of senescent marker expression in ZF1 treated cells. Additionally, Figure 9 shows that the treatment with ZF1 at the investigated concentration did not alter the cellular morphology, as compared with the control cells, as previously discussed in Section 2.2. 


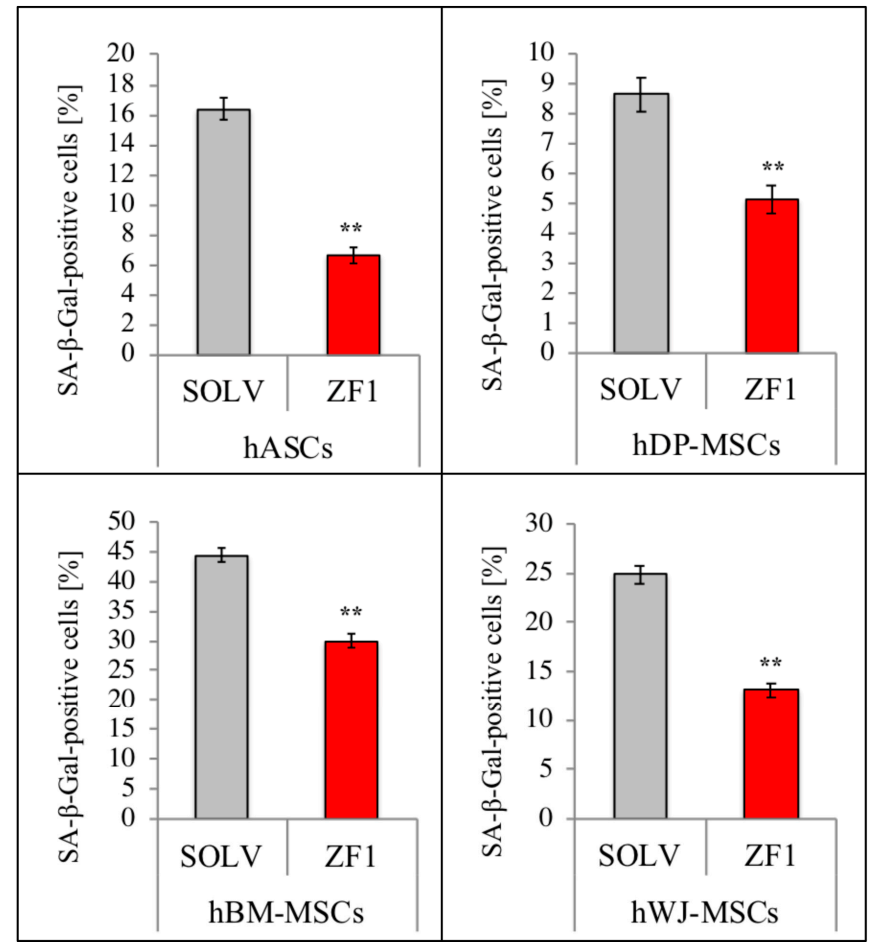

Figure 8. ZF1 counteracts SA $\beta$-gal activity in hMSCs. The hMSCs (culture passages 5 th-7th) were cultured for $72 \mathrm{~h}$ in the presence of $20 \mu \mathrm{g} / \mathrm{mL} \mathrm{ZF1}$, or a solvent as a control (SOLV). Then, cells were processed for SA $\beta$-gal assessment, as described in Figure 4 legend. The experiments with hASCs, hDP-MSCs, hBM-MSCs, and hWJ-MSCs were all performed with cells derived from three subjects. Data represent the percentage of SA $\beta$-gal positive cells calculated as the number of positive cells divided by the total number of counted cells multiplied by 100. All ZF1 treated cells were significantly different from the control group (Proportion in $\% \pm S D, n=3$ ). Statistical significance was evaluated using the Z-test for proportional, ${ }^{* *} p<0.01$.

\section{hASCs}

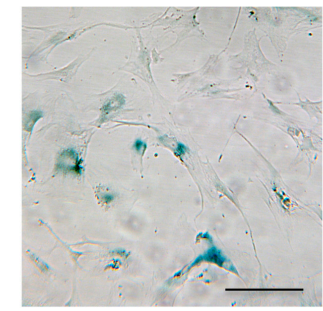

ZF1

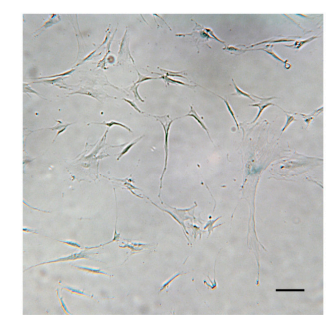

hDP-MSCs
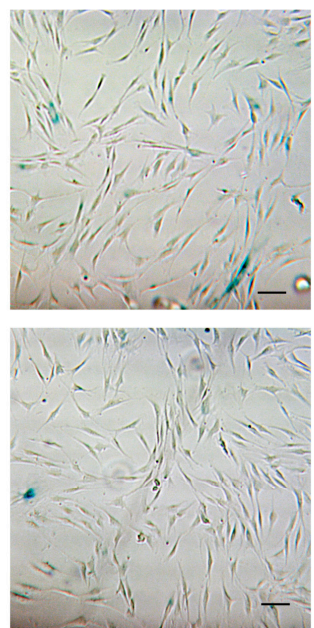
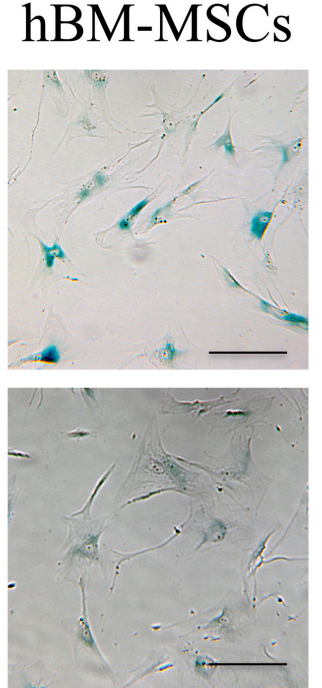
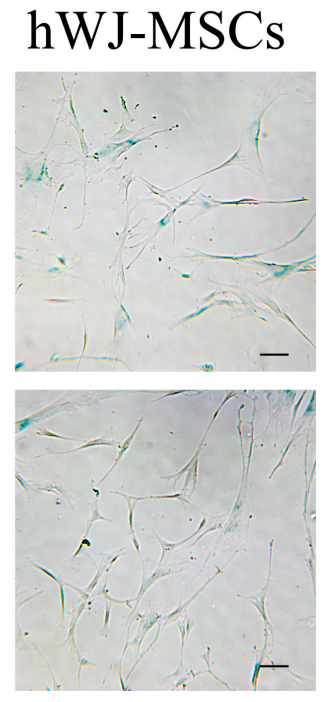

Figure 9. Representative images of the effects of ZF1 treatment on SA $\beta$-gal activity in hMSCs. The hMSCs from different sources (culture passages 5th-7th) were treated with $20 \mu \mathrm{g} / \mathrm{mL}$ ZF1 or with a solvent (SOLV) as a control, and then analyzed for SA $\beta$-gal expression (blue color, $200 \times$ magnification and bright field illumination). Images are representative of three separate experiments $(n=3)$ for each hMSC type. 


\subsection{ZF1 and Transcriptional Modulation of Stem Cell Senescence in Multisource hMSCs}

The relative quantitative real-time PCR (qPCR) analysis revealed that hASCs, hBM-MSCs, hDP-MSCs, and hWJ-MSCs (culture passages 5th-7th) all responded to a 72-h treatment with $20 \mu \mathrm{g} / \mathrm{mL}$ ZF1 with an evident increase in TERT gene transcription as compared with the ZF1 unexposed (control) cells (Figure 10). Next, we investigated whether ZF1 may have elicited its anti-senescence effect by acting on the transcription of other senescence modulators. In Figure 10a, we show that, in hASCs, $\mathrm{ZF1}$ was also able to enhance the gene expression of BMI1, a pleiotropic transcriptional regulator acting as a major repressor of senescence [44-46], while the exposure to ZF1 of hBM-MSCs, hDP-MSCs or hWJ-MSCs resulted in a nonsignificant effect on BMI1 transcription (Figure 10b, 10c, and 10d). Moreover, in hASCs, the treatment with ZF1 failed to affect the transcription of TP53 ( $p 53$ ), as well as the gene expression of type $1 \mathrm{~A}$ and $2 \mathrm{~A}$ cyclin dependent kinase inhibitors, CDKN1A ( $p 21$ ) and CDKN2A (p16) (Figure 10a). On the contrary, in hBM-MSCs, hDP-MSCs, and hWJ-MSCs, the ZF-induced increase in TERT transcription was associated with a down-regulation in both TP53 (p53) and CDKN1A ( $p 21)$ transcription, with no significant changes in CDKN2A ( $p 16)$ gene expression (Figure 10b-d, respectively).

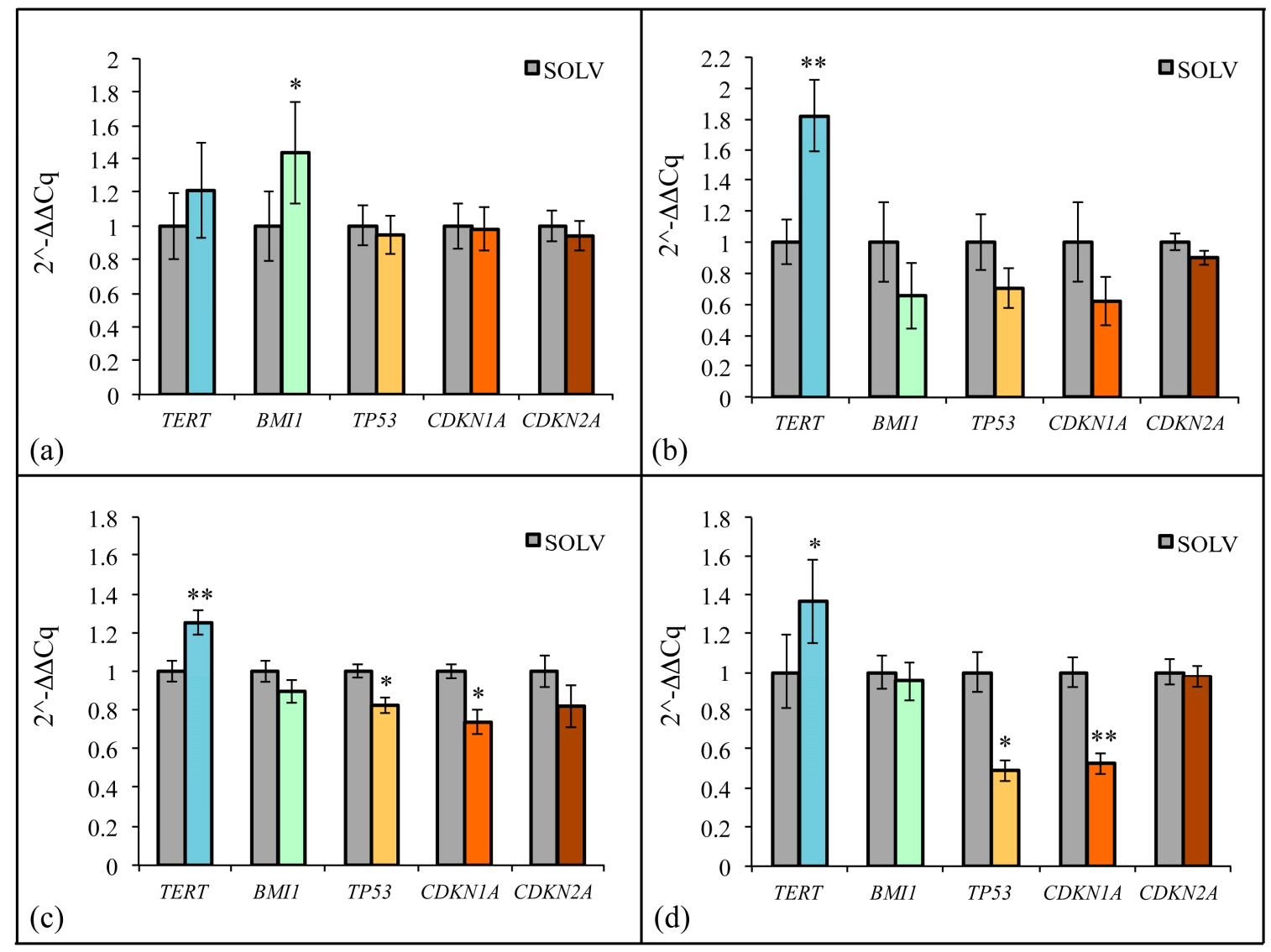

Figure 10. Effect of ZF1 on gene expression in hMSCs. The hASCs (a), hBM-MSCs (b), hDP-MSCs

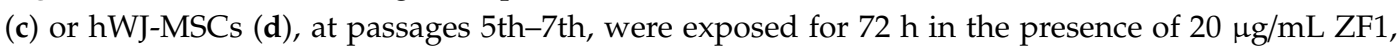
or a solvent (SOLV) as a control. The expression value of the transcripts evaluated in the solvent or ZF1-treated cells, was normalized to the expression levels of three reference genes, HPRT1, GAPDH, and TBP. The amount of the target mRNA in the ZF1 treated cells was plotted as the fold change over the expression in the control cells. The experiments were all performed with cells derived from three subjects. Statistical significance was evaluated by using the CFX Manager Software version 3.1 (Bio-Rad Laboratories) and the Student's $t$-test (mean $\pm \mathrm{SD},{ }^{*} p<0.05,{ }^{* *} p<0.01, n=3$ ). 


\subsection{ZF1 and 21 Expression in Multisource hMSCs}

Consistent with the experiments assessing the effect of ZF1 on gene transcription, we decided to perform a protein investigation for $\mathrm{p} 21$, since it is the last protagonist of the TERT/p53/p21 pathway. Western blot analysis revealed that a 72-h treatment with $20 \mu \mathrm{g} / \mathrm{mL}$ ZF1 affected the expression of p21 protein in the investigated hMSCs (culture passages 5th-7th), as compared with the ZF1 unexposed (control) cells (Figure 11). In particular, we showed that in hASCs and in hBM-MSCs, the change of p21 expression was not significant, while the exposure of hDP-MSCs or hWJ-MSCs to ZF1 resulted in a statistically significant decrease of the protein, in accordance with the relative $p 21$ gene transcription (Figure 11).

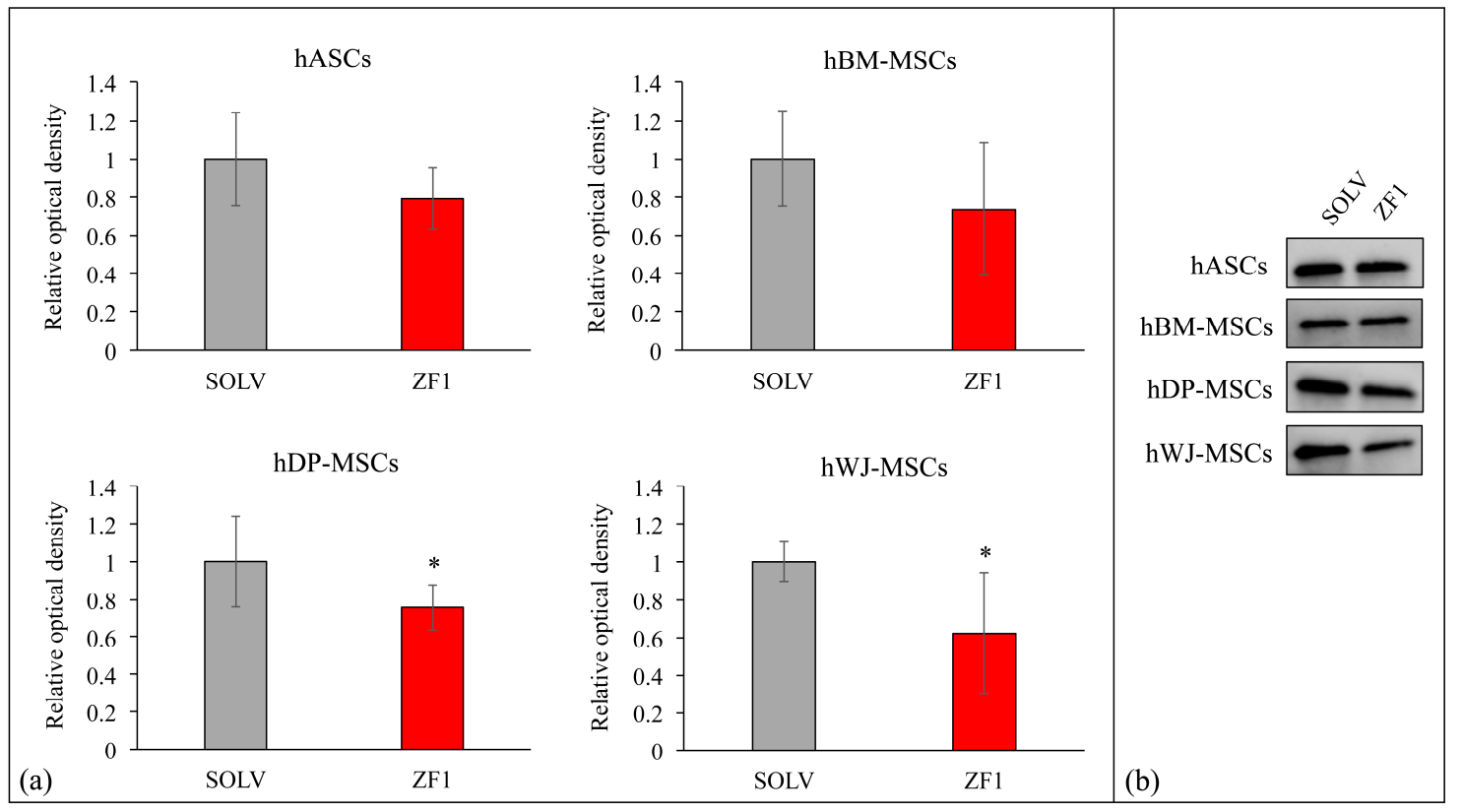

Figure 11. The Western blot analysis of p21 expression in SOLV- (as a control) and ZF1-treated hMSCs. (a) The graphs show the comparison of relative densitometric values of the bands normalized to total protein detected in stain-free acquisition in control (mean $\pm \mathrm{SD}$, statistical significance was evaluated using the Student's $t$-test, ${ }^{*} p<0.05, n=3$ ). (b) Representative images of the Western blot for each investigated cell type.

\subsection{ZF1 and Adipogenic Commitment in hMSCs}

The study of the role of ZF1 in hASC adipogenesis, described above, prompted us to extend our investigation to the other three hMSC types (hDP-MSCs, hBM-MSCs, and hWJ-MSCs), performed in technical triplicate. The hMSC adipogenic commitment was evident when cells were induced by adipogenic medium, as compared with cells grown in a culture medium (data not shown). The 72-h treatment with $20 \mu \mathrm{g} / \mathrm{mL}$ ZF1 increased the hASC adipogenic ability $(p<0.05)$ as compared with the ZF1 unexposed (control) cells, as previously described in preliminary experiments. In contrast, in hDP-MSCs, hBM-MSCs, and hWJ-MSCs, the results revealed that the treatment with ZF1 did not increase adipogenesis with statistical significance (Figure 12). 


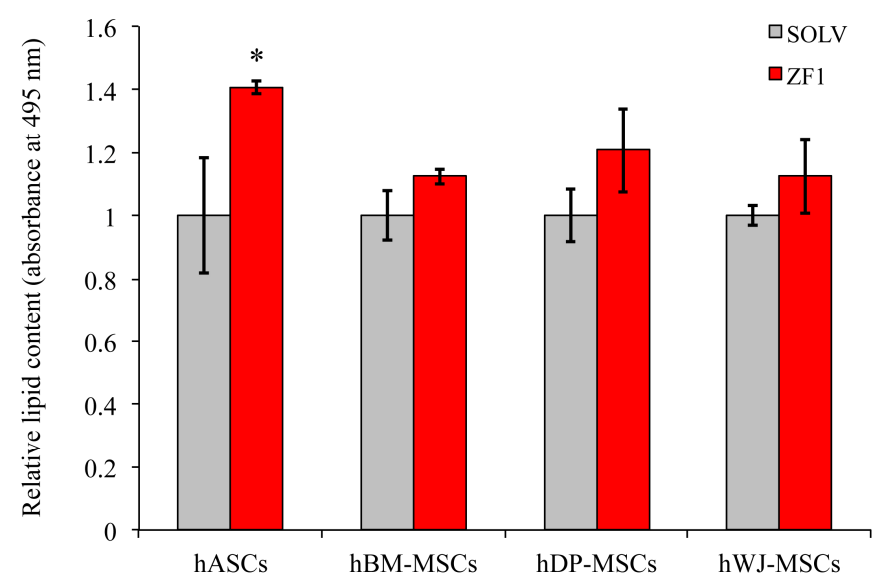

Figure 12. Effects of ZF1 treatment on adipogenic differentiation in hMSCs. The hASCs, hBM-MSCs, hDP-MSCs, and hWJ-MSCs, at the 5th passage, were exposed for $72 \mathrm{~h}$ in the presence of $20 \mu \mathrm{g} / \mathrm{mL}$ $\mathrm{ZF1}$, or a solvent as a control (SOLV). An experiment was performed in technical triplicate for each cell type. At the end of treatment, hMSCs were incubated with adipogenic medium for two weeks and then differentiation was assessed using Oil Red O staining. The lipid-rich vacuoles Oil Red O dye was extracted from each well and its absorbance was read at $495 \mathrm{~nm}$ with a spectrophotometer. Data are expressed as mean relative lipid content (absorbance at $495 \mathrm{~nm}$ ) of the ZF1 treated cells over the solvent treated ones (used as control, SOLV $=1$ ) \pm SD and statistical significance was evaluated using the Student's $t$-test, ${ }^{*} p<0.05, n=3$.

\section{Discussion}

The hMSCs are virtually present in all human organs and have different regenerative potential among the various tissue districts [47]. The properties of self-maintenance, multilineage differentiation, and trophic signaling that are exhibited by hMSCs make them highly attractive candidates for cell therapy approaches, endowing great advantages and peculiarities. The stem cell population that has been first isolated and characterized is hBM-MSCs. The hASCs and hDP-MSCs are commonly harvested in minimally invasive contexts, being abundant and rapidly proliferating stem cell populations, respectively. The hWJ-MSCs are obtained from discarded tissues and retain high plasticity and remarkable immunomodulatory properties due to their embryological and developmental origin [48-51]. In addition, the hMSCs from either adult or perinatal origins are not burdened by ethical problems and are supposed to be safer than embryonic stem cells or induced pluripotent stem (iPS) cells in terms of tumorigenesis and genomic modifications [52,53].

In an effort to use hMSCs from different tissue sources as potential tools for cell therapy, these cells are subjected to prolonged in vitro expansion in order to increase their number, and conceivably, their regenerative effect, prior to transplantation [10].

However, despite their diversity [54,55], all types of hMSCs undergo replicative senescence when cultured in vitro, a major drawback from the original assumption that tissue regeneration is promoted in a cell number-dependent fashion.

Here, we first show that the use of a developmentally defined zebrafish embryo extracted (ZF1) at concentrations of 10 and $20 \mu \mathrm{g} / \mathrm{mL}$ did not alter cell morphology and cell proliferation in hASCs as evidence of nontoxicity. Furthermore, ZF1 was able to counteract the hASC expression of a well-established senescence marker (SA $\beta$-gal) and it caused a significant increase in both induced and spontaneous adipogenic commitment, reinforcing our previous observations about hASCs $[25,26]$. In addition, similar effects on the $\beta$-gal activity were evident in other hMSCs that were investigated such as hBM-MSCs, hDP-MSCs, and hWJ-MSCs when treated with ZF1 at the defined concentration, however, adipogenic commitment was not significantly influenced. In particular, the different tissue origin could affect the MSC differentiation ability after ZF1 treatment [47,56]. 
In addition, the observed enhancement of TERT expression induced by ZF1 in all the investigated hMSC populations suggests that the rescue of a telomerase-dependent pathway could represent a common mechanism for the anti-senescence action of this embryo extract in hMSCs, independent of the stem cell source. The over-expression of TERT in hASCs reinforced the previously observed results in long-term cultures [26]. In particular, TERT expression is required to support optimal telomerase activity to counteract progressive telomere shortening and senescence [57]. Nevertheless, the observation, only in hASCs, that ZF1 enhanced the expression of BMI1, and the complex telomerase-dependent and -independent functions exploited by this chromatin remodeler in senescence repression $[58,59]$ suggests that the anti-senescence effect of ZF1 may also entail pleiotropic, which are still unexplored dynamics, depending on the MSC source. Such a hypothesis is further supported by the finding that different from hASCs, in hBM-MSCs, hDP-MSCs, and hWJ-MSCs the over-expression of TERT induced by ZF1 was associated with a down-regulation in TP53 (p53) transcription and in both the gene and protein CDKN1A (p21) expression. In these hMSC types the opposite transcriptional responses induced by ZF1 may converge to potentiate the anti-senescence response as it may be inferred by the fact that the loss of p53 function has been found to accelerate telomerase activity [60], and that senescent cells upregulate cell cycle inhibitors (such as p53 and p21) [61]. Therefore, the observation that p53-dependent transcriptional repression of TERT was mediated by CDKN1A ( $p 21$ ) in both normal and pathologic cells $[62,63]$ indicates that the down-regulation of TP53 (p53) and CDKN1A ( $p 21)$, concomitant with TERT over-expression, may be part of a delicate circuitry through which ZF1 could affect senescence in hMSCs in a source-dependent manner, since a similar pattern was not observed in hASCs in response to ZF1 treatment. The lack of an effect of ZF1 on CDKN2A ( $p 16)$ transcription in all investigated hMSCs suggests that ZF1 action may not involve previously reported BMI1/p16/pRB pathways [58,59].

Compounding the complexity of the putative mechanisms underlying the speculated anti-senescence response elicited by ZF1 are recent observations that provide evidence for a novel function of TERT in stem cell activation, which is independent of telomerase activity, as shown by the promoting effect on hair growth by TERT over-expression in a mouse strain that is lacking the RNA component of telomerase [64]. In this regard, it has also been found that TERT has a role in activating stem cells which is mediated by the transcriptional activation of a developmental program converging on Myc and Wnt signaling [65]. Therefore, the ZF1-mediated increase in TERT transcription may also involve a pleiotropic activation of stem cells, counteracting their senescence in a manner which is independent of the synthesis of telomere repeats. Further studies are in progress to discriminate among these putative telomerase-dependent and -independent pathways in hMSC response to ZF1. In fact, to date, we only have evidence about the ZF1 effect on telomerase activity in a long-term culture of hASCs [26]. As a next step, we plan to further investigate telomerase activity in other hMSCs under different experimental conditions. Starting from the information currently available on the presence of defined transcripts and proteins in zebrafish at the developmental stage of $50 \%$ epiboly [36,41], we will attempt to identify putative conductors capable of recapitulating the biological program observed in the present study.

On the whole, our results suggest that the anti-senescence action elicited by ZF1 on multisource hMSCs can be unfolded into two major, non-mutually exclusive, biomedical implications. Concerning the first implication, antagonizing stem cell senescence during prolonged in vitro culture may allow stem cells expansion up to the number precisely required for a targeted regenerative setting. As far as the second implication is concerned, the anti-senescence action promoted in vitro by ZF1 could be conceivably deployed in vivo using the extract to target the stem cells where they are in all body tissues and afford a process of tissue rejuvenation without the need for stem cell transplantation.

In future studies we are committed to extending the characterization of ZF1 composition and action, and also to addressing the potential limits, which include alterations in genome stability and eventual tumorigenic drift. We also plan to investigate the ZF1 effect on senescence progression at late passages in multiple hMSC types, with particular emphasis on WJ-hMSCs. In fact, these perinatal 
hMSCs retain the chance for higher multilineage commitment than other adult hMSCs [66]. For this reason, WJ-hMSCs are particularly amenable for future off-the-shelf approaches of allogeneic cell therapy where cells are conceived for long-lasting banking (years) prior to transplantation, an issue that will require effective and precise control of senescence drift over the banking time.

\section{Materials and Methods}

\subsection{Ethics Statement}

All the tissue samples were obtained from subjects that gave their informed consent for inclusion before their participation in the study. The study was conducted in accordance with the Declaration of Helsinki, and the protocol was approved by the local ethical committees (CE) (S. Orsola-Malpighi University Hospital, project identification code: n.1645/2014, ref. 35/2014/U/Tess and Villalba Hospital, project identification code: 16076 of Bologna, Italy).

\section{2. hMSCs Harvesting and Culture}

hASCs Human subcutaneous adipose tissue samples (obtained from 3 subjects) were isolated from lipoaspiration procedures and processed by using the Lipogems device (PCT/IB2011/052204), as previously described [43]. A volume of $1.5 \mathrm{~mL}$ of Lipogems product containing hASCs was seeded in a T75 flask (Falcon BD, Bedford, MA, USA) precoated with human fibronectin $\left(0.55 \mu \mathrm{g} / \mathrm{cm}^{2}\right)$ (Sigma-Aldrich Co., St. Louis, MO, USA) and human collagen I-III $\left(0.50 \mu \mathrm{g} / \mathrm{cm}^{2}\right)($ ABCell-Bio, Paris, France) and cultured in alfa-minimal essential medium ( $\alpha$-MEM, Carlo Erba Reagents, Milano, Italy) supplemented with $10 \%$ heat-inactivated fetal bovine serum (FBS) (Gibco, Waltham, MA, USA), $1 \%$ penicillin-streptomycin solution, 1\% L-glutamine $200 \mathrm{mM}$ (Carlo Erba Reagents).

hDP-MSCs Vital human molars were obtained from 3 adult subjects during routine dental extraction. Dental pulp tissue fragments were recovered and digested as previously described [67]. The hDP-MSCs, slipped down from the explants, were isolated and cultured in Dulbecco's modified Eagle's medium high glucose (DMEM, BioWhittaker Cambrex, Walkersville, MD, USA) in the presence of $10 \%$ FBS (Gibco) and antibiotics (100 U/mL penicillin, $100 \mu \mathrm{g} / \mathrm{mL}$ streptomycin and $0.25 \mu \mathrm{g} / \mathrm{mL}$ amphotericin B) (Carlo Erba Reagents).

hBM-MSCs Bone marrow was collected from 3 healthy adult volunteers and treated as previously described [68]. The isolated hBM-MSCs were plated at $1 \times 10^{6} / \mathrm{cm}^{2}$ in culture flasks in DMEM high glucose (BioWhittaker Cambrex) supplemented with 20\% FBS (Gibco) and antibiotics (200 U/mL penicillin, $200 \mu \mathrm{g} / \mathrm{mL}$ streptomycin) (Carlo Erba Reagents).

hWJ-MSCs Umbilical cords from 3 healthy donor mothers obtained from caesarean sections were rapidly transferred to the laboratory and treated as previously described [69]. Cord fragments with an approximate diameter of $2 \mathrm{~mm}$ were seeded onto the surface of a culture dish with DMEM low glucose (BioWhittaker Cambrex) supplemented with 10\% FBS (Gibco), penicillin and streptomycin $200 \mu \mathrm{g} / \mathrm{mL}$ (Carlo Erba Reagents).

All investigated cell lines were incubated at $37^{\circ} \mathrm{C}$ in a humidified atmosphere with $5 \% \mathrm{CO}_{2}$. The non-adherent cells were removed, and the medium was changed subsequently every $2-4$ days. Confluent cells were detached by treatment with trypsin-EDTA (Sigma-Aldrich Co.), maintained and expanded until the desired culture passages.

Before their experimental use, mesenchymal stem cells obtained from all investigated culture tissues at the same doubling passage were observed under the optical microscope (at $40 \times$ magnification and bright field illumination). Therefore, cells were analyzed with flow cytometry to confirm the presence of minimal criteria for defining multipotent mesenchymal stem cells, in accordance with the International Society for Cellular Therapy [8]. 


\subsection{Zebrafish Embryo Extract, Dose Analysis and Treatments}

Zebrafish embryos were harvested and processed as previously described [25,70]. The $50 \%$ epiboly ( $5 \mathrm{~h}$ and $15 \mathrm{~min}$ post-fertilization, hpf) developmental stage (named here ZF1) was chosen and the extract containing eggs at the density of $100 / \mathrm{mL}$ was prepared in a glycero-alcoholic solution ( $60 \%$ glycerol, $5 \%$ ethanol, $0.12 \%$ potassium sorbate and $0.08 \%$ sodium benzoate) and stored at $4{ }^{\circ} \mathrm{C}$ until use, according to the manufacturer's standard protocol (Aurora Biosearch, Bollate, Milano, Italy). The ZF1 extract was previously analysed on a one-dimensional sodium dodecyl sulphate-polyacrylamide gel electrophoresis (SDS-PAGE) and its proteic content was characterized by using liquid chromatography-tandem mass spectrometry (LC-MS/MS) [41]. In order to evaluate the eligible ZF1 dose to use in the present work, hASCs were first treated for $72 \mathrm{~h}$ with ZF1 at five different concentrations $(0.01,10,20,40$, and $100 \mu \mathrm{g} / \mathrm{mL}$ ), analyzed under a light microscope (at 200× magnification and bright field illumination), and then submitted to preliminary analyses. On the basis of the results from these treatments, investigated hMSCs were cultured with $20 \mu \mathrm{g} / \mathrm{mL}$ ZF1 for $72 \mathrm{~h}$ in all experiments. An equal amount of ZF1 solvent (a glycero-alcoholic solution) was used as a control in all experiments except in the resazurin-based assay where both control and solvent were used.

\subsection{BCA Protein Assay}

The protein content of ZF1 was determined using a BCA protein assay kit, following the manufacturer's instructions (Pierce Biotechnology, Rockford, IL, USA). As previously described, the protein content of the extract was determined using a Nanodrop instrument (Nanodrop ND 1000 v.3.8.1, Wilmington, DE, USA), with serial dilution of bovine serum albumin as a standard [25].

\subsection{In Vitro Resazurin-Based Toxicology Assay}

To evaluate the ZF1 cell proliferation as a function of metabolic activity of the cells, In Vitro Toxicology Assay kit, resazurin-based, (Sigma-Aldrich Co.) was preliminarily used on the hASCs at the 5th culture passage, as representative of the investigated mesenchymal cells. These cells were seeded in technical quadruplicate in a 96-well plate at $4000 \mathrm{cells} / \mathrm{cm}^{2}$. After $24 \mathrm{~h}$ in standard conditions, cells were treated for $72 \mathrm{~h}$ with ZF1 at three different concentrations $(0.01,10$, and $20 \mu \mathrm{g} / \mathrm{mL})$, or with a solvent (in equal amount), or were untreated (control cells) and were cultured at $37^{\circ} \mathrm{C}$ in a complete medium with resazurin reagent (at the ratio of 10:1, respectively). In each experiment, negative (blue resazurin solution with medium) and positive (red totally-reduced resazurin with medium) controls in the absence of cells were added. Fluorescence (correlated to the presence of reduced resazurin as marker of cell metabolic activity over time) was measured after 4, 24, 48, and $72 \mathrm{~h}$ from the beginning of the treatment with the Wallac 1420 Victor2 multilabel counter (Perkin Elmer, Waltham, MA, USA) at an emission wavelength of $590 \mathrm{~nm}$ and an excitation wavelength of $560 \mathrm{~nm}$. The number of viable cells correlating with the magnitude of dye reduction was expressed as a percentage of resazurin reduction according to this formula: (FI 590 of test agent-FI 590 of negative control)/(FI 590 of 100\% reduced of resazurin-FI 590 negative control) $\times 100$, where FI means fluorescence intensity.

Then, the same experiments were extended to hMSCs isolated from four sources (hASCs, hDP-MSCs, hBM-MSCs, and hWJ-MSCs), and ZF1 at the concentration of $20 \mu \mathrm{g} / \mathrm{mL}$ was used. Each treatment was performed in quadruplicate and the whole experiment was repeated with cells obtained from three different subjects (culture passages spanning from the 5th to the 7th).

\subsection{Senescence-Associated $\beta$-Galactosidase Staining}

Cell staining was performed using a SA $\beta$-gal kit (Cell Signaling, Danvers, MA, USA). Briefly, all investigated hMSCs were seeded at culture passages between 5 th and 7th in 6-well plates (Falcon BD) at the density of 2000 cells $/ \mathrm{cm}^{2}$. After $24 \mathrm{~h}$ in standard conditions, cells were treated for $72 \mathrm{~h}$ with ZF1 or with a solvent as a control. The preliminary experiments were conducted by using three $\mathrm{ZF1}$ different concentrations $(0.01,10$, and $20 \mu \mathrm{g} / \mathrm{mL})$ in hASCs $(n=3)$. Then the experiments were 
extended to hMSCs isolated from four sources (hASCs, hDP-MSCs, hBM-MSCs, and hWJ-MSCs) using $\mathrm{ZF} 1$ only at the concentration of $20 \mu \mathrm{g} / \mathrm{mL}$ for $72 \mathrm{~h}$ and at the different density of $1770 \mathrm{cells} / \mathrm{cm}^{2}$ for hWJ-MSCs. Each treatment was performed in duplicate and the whole experiment was repeated with cells obtained from three different subjects. Cells were fixed and processed according to the manufacturer's instructions. The number of positive (blue) and negative (not colored) cells was counted in each sample in at least three random fields under the microscope (at 200× magnification and bright field illumination) and the percentage of SA $\beta$-gal-positive cells was calculated as the number of positive cells divided by the total number of cells counted multiplied by 100 [71,72].

\subsection{Adipogenic Differentiation}

The hASCs at culture passages between 5th and 7th $(n=3)$ were tested for their ability to differentiate into adipogenic lineage. The hASCs were cultured on 24-well plates at the density of 15,000 cells/well. After $24 \mathrm{~h}$ in standard conditions, cells were treated for $72 \mathrm{~h}$ with $\mathrm{ZF} 1$ at three different concentrations $(0.01,10$, and $20 \mu \mathrm{g} / \mathrm{mL}$ ), or with a solvent as a control. Each treatment (ZF1 at different doses and solvent) was performed in six wells. At the end of the treatment, 4 wells were incubated with adipogenic medium (hMSC adipogenic differentiation medium, Lonza, Walkersville, MD, USA), which was changed twice a week for two weeks. The other two wells were not induced with adipogenic medium but cultured in a standard medium. At the end of the two weeks, differentiation was assessed using Oil Red O staining, as previously described [73]. In particular, cells were fixed in $10 \%$ formalin at room temperature for $15 \mathrm{~min}$, washed in distilled water and incubated for $15 \mathrm{~min}$ with Oil Red O solution. Then, the cell monolayer was washed three times with demineralized $\mathrm{H}_{2} \mathrm{O}$. Finally, Oil Red $\mathrm{O}$ was extracted by incubation with isopropanol for $10 \mathrm{~min}$ in moderate agitation. For each well, the dye was aliquoted and transferred in triplicate to a 96-well plate prior to reading absorbance at $495 \mathrm{~nm}$ using a spectrophotometer (Victor 2, Perkin Elmer Wallac, Milan, Italy).

Furthermore, the adipogenic differentiation assay was extended to hMSCs isolated from four sources (hASCs, hDP-MSCs, hBM-MSCs, and hWJ-MSCs) at the 5th culture passage. A ZF1 concentration of $20 \mu \mathrm{g} / \mathrm{mL}$ was used, and for each investigated hMSC type a technical triplicate was performed $(n=3)$.

\subsection{RNA Extraction and RT-PCR}

The hMSCs obtained from the investigated sources, were seeded in T25 flasks at the density of 3500 cells $/ \mathrm{cm}^{2}$ (culture passages $5 \mathrm{th}-7 \mathrm{th}$ ) and incubated in standard conditions for $24 \mathrm{~h}$ before treatments.

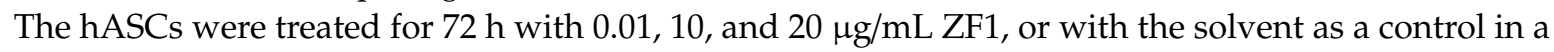
preliminary experiment (technical triplicate), and subsequently, each type of MSCs was treated for $72 \mathrm{~h}$ with $20 \mu \mathrm{g} / \mathrm{mL}$ ZF1, or with the solvent as a control. For each type of MSCs, the whole experiment was repeated in biological triplicate. Total RNA was extracted from all investigated cell lineages using the RNeasy mini kit (QIAGEN, Valencia, CA, USA) following the manufacturer's instructions. The genomic DNA contamination was removed by digestion with RNase-free deoxyribonuclease I (RNase-free DNase set, QIAGEN). The reverse transcription of the extracted RNA was performed as previously described except for the temperature of the reaction that was $37^{\circ} \mathrm{C}$ instead of $42{ }^{\circ} \mathrm{C}$ [74]. The success of the reaction was verified by the amplification of the human Glyceraldehyde 3-phosphate dehydrogenase $(G A P D H)$ gene, using specific primers (forward sequence: 5'-GAAATCCCATCACCATCTTCCAG-3' and reverse sequence $5^{\prime}$-GCTACACTGAGCACCAGGTGGTCTCCT-3'). The GAPDH amplification was performed as previously described [75], for 25 cycles instead of 45 . The amplicon detection was performed by gel electrophoresis as previously described [25].

\subsection{Real-Time PCR}

A relative quantitative real-time PCR (qPCR) was performed in a Bio-Rad CFX96 real-time thermal cycler (Bio-Rad Laboratories, Hercules, CA, USA) as previously described [76]. Briefly, $25 \mathrm{ng}$ of cDNA were amplified using the SsoAdvanced Universal SYBR Green Supermix (Bio-Rad Laboratories) in technical triplicate for every cDNA sample. Primers for TERT were purchased 
from Invitrogen (forward sequence: $5^{\prime}$-AAGTTCCTGCACTGGCTGATG- $3^{\prime}$ and reverse sequence $5^{\prime}$-GCTTTGCAACTTGCTCCAGAC-3') (Invitrogen, Carlsbad, CA, USA) and were used as $0.2 \mu \mathrm{M}$ each in the qPCR reactions. Specific primers for BMI1, TP53, CDKN1A ( $p 21$ ), and CDKN2A ( $p 16$ ) (unique assay ID: qHsaCED0046537, qHsaCID0013658, qHsaCID0014498 and qHsaCED0056722, respectively, Bio-Rad Laboratories) were designed by Bio-Rad and used following the manufacturer's instructions (20x, Bio-Rad Laboratories).

Relative gene expression was determined using CFX Manager Software version 3.1 (Bio-Rad Laboratories) with the "delta-delta CT method" [77] and hypoxanthine phosphoribosyl transferase 1 (HPRT1), TATA box binding protein (TBP), GAPDH (20×, unique assay ID: qHsaCID0016375, qHsaCID0007122, qHsaCED0038674, respectively, Bio-Rad Laboratories) were used as reference genes. The investigated mRNA levels in hASCs, hDP-MSCs, hBM-MSCs, and hWJ-MSCs treated with ZF1 $20 \mu \mathrm{g} / \mathrm{mL}$ were expressed as fold of change $\left(2^{-\Delta \Delta C t}\right)$, relative to mRNA levels evaluated in respective hMSC lines treated with a solvent as a control. A preliminary gene expression analysis with qPCR was conducted to exclude effects of the treatment with solvent. Gene expression analysis was performed in biological triplicate for each cell type.

\subsection{Protein Extraction and Western Blot}

All investigated hMSCs were seeded at culture passages between 5th and 7th in T25 flasks (Falcon $\mathrm{BD})$ at the density of 3500 cells $/ \mathrm{cm}^{2}$. After $24 \mathrm{~h}$ in standard conditions, cells were treated for $72 \mathrm{~h}$ with ZF1 $20 \mu \mathrm{g} / \mathrm{mL}$ or with a solvent as a control.

At the end of the treatment, cells were scraped from the flasks and pelleted at $1200 \mathrm{rpm}$ for $5 \mathrm{~min}$. Pellets were lysed with the mammalian protein extraction reagent (M-PER, Thermo-Fisher Scientific, Waltham, MA, USA) supplemented with 100× protease and phosphatase inhibitors (Sigma-Aldrich). Then, cell lysates were subjected to 3 cycles of $5 \mathrm{~s}$ of sonication followed by $2 \mathrm{~min}$ in ice and then centrifuged at the maximum speed to remove the cellular debris. The protein content of each sample was determined using a Bradford kit (VWR International, Radnor, Pennsylvania, USA).

Before electrophoresis, every sample was mixed with $4 \times$ Laemmly sample buffer (Bio-Rad) supplemented with a $10 \%$ of 2-mercaptoethanol (Sigma-Aldrich) and then boiled at $95^{\circ} \mathrm{C}$ for $5 \mathrm{~min}$.

An amount of $10 \mu \mathrm{g}$ of proteins were loaded in Mini-PROTEAN TGX stain-free precast protein gels (Bio-Rad) and electrophoresis was performed in a 10× tris/glycine/SDS buffer (Bio-Rad) with the Mini-PROTEAN Tetra System (Bio-Rad). Gels and total protein amount were analyzed with ChemiDoc imaging system (Bio-Rad). Blotting was performed using a Trans-Blot Turbo Transfer Pack and a Trans-Blot Turbo Transfer System (Bio-Rad). After a blocking step of $1 \mathrm{~h}$ in a 3\% solution of milk (Blotting Grade Blocking; Bio-Rad) in TBS-Tween $0.1 \%$, membranes were incubated overnight at $4{ }^{\circ} \mathrm{C}$ with the p21 (Santa Cruz Biotechnologies, Dallas, Texas, USA) primary antibody used 1:1000 and $1 \mathrm{~h}$ at room temperature with the appropriate secondary antibody, diluted 1:5000 (Santa Cruz Biotechnologies). Protein detection was performed after 1 min of incubation with Clarity Max Western ECL substrate (Bio-Rad) and image acquired using ChemiDoc Touch Imaging System (Bio-Rad). The detected signal for each sample was normalized to the total protein detected in stain-free acquisitions. The Western blot analysis was performed in biological triplicate for each cell type.

\subsection{Statistical Analysis}

Data obtained from in vitro toxicology assay were investigated with ANOVA analysis followed by the Tukey HSD test. Data obtained from the SA $\beta$-gal assay were analyzed using the Student's $t$-test in preliminary experiment and Z-test for proportional in the study of the four types of hMSCs treated with ZF1 $20 \mu \mathrm{g} / \mathrm{mL}$. Data obtained from the adipogenesis assay and the Western blot were analyzed using the Student's $t$-test. Data obtained from qPCR were analyzed using the CFX Manager Software version 3.1 (Bio-Rad Laboratories) and the Student's $t$-test. The results were considered statistically significant with a $p$-value $<0.05$ and highly significant with a $p$-value $<0.01$. 
Author Contributions: F.F. and F.A. conceived and executed the experimental plan; S.C., E.B., and M.R. performed the experiments; F.F., F.A., S.C., E.B., and C.V. analyzed the data; C.V. designed/supervised the project; C.V., F.F., F.A., and S.C. wrote the manuscript; L.B., R.C., and P.M.B. collaborated in conceiving the experimental plan; all authors reviewed the manuscript.

Funding: This research was funded by the Eldor Lab, via Vittor Pisani 16, 20124 Milan, Italy.

Acknowledgments: The statisticians Barbara Bordini and Umberto Santoro are gratefully acknowledged for their contribution.

Conflicts of Interest: The authors declare no conflict of interest.

\section{Abbreviations}

$\begin{array}{ll}\alpha \text {-MEM } & \text { alfa-Minimal Essential Medium } \\ \text { BMI1 } & \text { BMI1 proto-oncogene, polycomb ring finger } \\ \text { BM } & \text { bone marrow } \\ \text { CDKN1A (p21) } & \text { cyclin dependent kinase inhibitor 1A } \\ \text { CDKN2A (p16) } & \text { cyclin dependent kinase inhibitor 2A } \\ \text { c-Myc } & \text { v-myc avian myelocytomatosis viral oncogene homolog } \\ \text { CTR } & \text { control } \\ \text { DP } & \text { dental pulp } \\ \text { DMEM } & \text { Dulbecco's Modified Eagle's Medium } \\ \text { FBS } & \text { Fetal Bovine Serum } \\ \text { GAPDH } & \text { glyceraldehyde 3-phosphate dehydrogenase } \\ \text { h } & \text { hour } \\ \text { hpf } & \text { hours post fertilization } \\ \text { hMSCs } & \text { human mesenchymal stem cells } \\ \text { hASCs } & \text { human adipose tissue-derived stem cells } \\ \text { HPRT1 } & \text { hypoxanthine phosphoribosyl transferase 1 } \\ \text { iPS } & \text { induced pluripotent stem } \\ \text { LC-MS/MS } & \text { liquid chromatography-tandem mass spectrometry } \\ \text { OCT-4 } & \text { POU domain class 5 homeobox 1 (POU5F1), alias Oct-4 } \\ \text { qPCR } & \text { quantitative relative real-time PCR } \\ \text { SA } \beta \text {-gal } & \text { Senescence-Associated } \beta \text {-Galactosidase } \\ \text { SDS-PAGE } & \text { Sodium Dodecyl Sulphate-Polyacrylamide Gel Electrophoresis } \\ \text { SOLV } & \text { solvent } \\ \text { TBP } & \text { TATA box binding protein } \\ \text { TERT } & \text { telomerase reverse transcriptase } \\ \text { TP53 } & \text { tumor protein p53 } \\ \text { WJ } & \text { Wharton's Jelly } \\ \text { ZF1 } & \end{array}$

\section{References}

1. Bryder, D.; Rossi, D.J.; Weissman, I.L. Hematopoietic stem cells: The paradigmatic tissue-specific stem cell. Am. J. Pathol. 2006, 169, 338-346. [CrossRef] [PubMed]

2. Asahara, T.; Kawamoto, A. Endothelial progenitor cells for postnatal vasculogenesis. Am. J. Physiol. Cell Physiol. 2004, 287, C572-C579. [CrossRef]

3. Murry, C.E.; Field, L.J.; Menasche, P. Cell-based cardiac repair: Reflections at the 10-year point. Circulation 2005, 112, 3174-3183. [CrossRef]

4. Lindvall, O.; Kokaia, Z.; Martinez-Serrano, A. Stem cell therapy for human neurodegenerative disorders-how to make it work. Nat. Med. 2004, 10, S42-S50. [CrossRef]

5. Bonner-Weir, S.; Weir, G.C. New sources of pancreatic beta-cells. Nat. Biotechnol. 2005, 23, 857-861. [CrossRef] [PubMed]

6. Bianco, P.; Riminucci, M.; Gronthos, S.; Robey, P.G. Bone marrow stromal stem cells: Nature, biology, and potential applications. Stem Cells 2001, 19, 180-192. [CrossRef] 
7. Crisan, M.; Yap, S.; Casteilla, L.; Chen, C.W.; Corselli, M.; Park, T.S.; Andriolo, G.; Sun, B.; Zheng, B.; Zhang, L.; et al. A perivascular origin for mesenchymal stem cells in multiple human organs. Cell Stem Cell 2008, 3, 301-313. [CrossRef]

8. Dominici, M.; Le Blanc, K.; Mueller, I.; Slaper-Cortenbach, I.; Marini, F.; Krause, D.; Deans, R.; Keating, A.; Prockop, D.J.; Horwitz, E. Minimal criteria for defining multipotent mesenchymal stromal cells. The International Society for Cellular Therapy position statement. Cytotherapy 2006, 8, 315-317. [CrossRef] [PubMed]

9. Wei, X.; Yang, X.; Han, Z.P.; Qu, F.F.; Shao, L.; Shi, Y.F. Mesenchymal stem cells: A new trend for cell therapy. Acta Pharmacol. Sin. 2013, 34, 747-754. [CrossRef] [PubMed]

10. Mahla, R.S. Stem cells applications in regenerative medicine and disease therapeutics. Int. J. Cell Biol. 2016, 2016, 6940283. [CrossRef]

11. Bai, L.; Lennon, D.P.; Caplan, A.I.; DeChant, A.; Hecker, J.; Kranso, J.; Zaremba, A.; Miller, R.H. Hepatocyte growth factor mediates mesenchymal stem cell-induced recovery in multiple sclerosis models. Nat. Neurosci. 2012, 15, 862-870. [CrossRef]

12. Chang, C.; Wang, X.; Niu, D.; Zhang, Z.; Zhao, H.; Gong, F. Mesenchymal stem cells adopt beta-cell fate upon diabetic pancreatic microenvironment. Pancreas 2009, 38, 275-281. [CrossRef]

13. Kuo, Y.R.; Goto, S.; Shih, H.S.; Wang, F.S.; Lin, C.C.; Wang, C.T.; Huang, E.Y.; Chen, C.L.; Wei, F.C.; Zheng, X.X.; et al. Mesenchymal stem cells prolong composite tissue allotransplant survival in a swine model. Transplantation 2009, 87, 1769-1777. [CrossRef]

14. Souza, B.S.; Nogueira, R.C.; de Oliveira, S.A.; de Freitas, L.A.; Lyra, L.G.; Ribeiro dos Santos, R.; Lyra, A.C.; Soares, M.B. Current status of stem cell therapy for liver diseases. Cell Transplant. 2009, 18, 1261-1279. [CrossRef]

15. Quevedo, H.C.; Hatzistergos, K.E.; Oskouei, B.N.; Feigenbaum, G.S.; Rodriguez, J.E.; Valdes, D.; Pattany, P.M.; Zambrano, J.P.; Hu, Q.; McNiece, I.; et al. Allogeneic mesenchymal stem cells restore cardiac function in chronic ischemic cardiomyopathy via trilineage differentiating capacity. Proc. Natl. Acad. Sci. USA 2009, 106, 14022-14027. [CrossRef]

16. Facchin, F.; Bianconi, E.; Canaider, S.; Basoli, V.; Biava, P.M.; Ventura, C. Tissue Regeneration without Stem Cell Transplantation: Self-Healing Potential from Ancestral Chemistry and Physical Energies. Stem Cells Int. 2018, 2018, 7412035. [CrossRef]

17. Castorina, A.; Szychlinska, M.A.; Marzagalli, R.; Musumeci, G. Mesenchymal stem cells-based therapy as a potential treatment in neurodegenerative disorders: Is the escape from senescence an answer? Neural Regen. Res. 2015, 10, 850-858. [CrossRef]

18. Szychlinska, M.A.; Stoddart, M.J.; D'Amora, U.; Ambrosio, L.; Alini, M.; Musumeci, G. Mesenchymal Stem Cell-Based Cartilage Regeneration Approach and Cell Senescence: Can We Manipulate Cell Aging and Function? Tissue Eng. Part. B Rev. 2017, 23, 529-539. [CrossRef]

19. Tal, T.L.; Franzosa, J.A.; Tanguay, R.L. Molecular signaling networks that choreograph epimorphic fin regeneration in zebrafish-A mini-review. Gerontology 2010, 56, 231-240. [CrossRef]

20. Shi, W.; Fang, Z.; Li, L.; Luo, L. Using zebrafish as the model organism to understand organ regeneration. Sci. China Life Sci. 2015, 58, 343-351. [CrossRef]

21. Goessling, W.; North, T.E. Repairing quite swimmingly: Advances in regenerative medicine using zebrafish. Dis. Model. Mech. 2014, 7, 769-776. [CrossRef]

22. Brockerhoff, S.E.; Fadool, J.M. Genetics of photoreceptor degeneration and regeneration in zebrafish. Cell Mol. Life Sci. 2011, 68, 651-659. [CrossRef]

23. Becker, T.; Becker, C.G. Axonal regeneration in zebrafish. Curr. Opin. Neurobiol. 2014, 27, 186-191. [CrossRef]

24. Pozzoli, O.; Vella, P.; Iaffaldano, G.; Parente, V.; Devanna, P.; Lacovich, M.; Lamia, C.L.; Fascio, U.; Longoni, D.; Cotelli, F; et al. Endothelial fate and angiogenic properties of human CD34+ progenitor cells in zebrafish. Arterioscler. Thromb. Vasc. Biol. 2011, 31, 1589-1597. [CrossRef]

25. Canaider, S.; Maioli, M.; Facchin, F.; Bianconi, E.; Santaniello, S.; Pigliaru, G.; Ljungberg, L.; Burigana, F.; Bianchi, F.; Olivi, E.; et al. Human stem cell exposure to developmental stage zebrafish extracts: A novel strategy for tuning stemness and senescence patterning. CellR4 2014, 2, e1226.

26. Facchin, F.; Canaider, S.; Bianconi, E.; Maioli, M.; Santoro, U.; Santaniello, S.; Basoli, V.; Biava, P.M.; Ventura, C. Zebrafish embryo extract counteracts human stem cell senescence. Front. Biosci. (Schol Ed.) 2019, 11, 89-104. [CrossRef] 
27. Mathavan, S.; Lee, S.G.; Mak, A.; Miller, L.D.; Murthy, K.R.; Govindarajan, K.R.; Tong, Y.; Wu, Y.L.; Lam, S.H.; Yang, H.; Ruan, Y.; et al. Transcriptome analysis of zebrafish embryogenesis using microarrays. PLoS Genet. 2005, 1, 260-276. [CrossRef]

28. Yao, Y.; Ma, L.; Jia, Q.; Deng, W.; Liu, Z.; Zhang, Y.; Ren, J.; Xue, Y.; Jia, H.; Yang, Q. Systematic characterization of small RNAome during zebrafish early developmental stages. BMC Genom. 2014, 15, 117. [CrossRef]

29. Palmblad, M.; Henkel, C.V.; Dirks, R.P.; Meijer, A.H.; Deelder, A.M.; Spaink, H.P. Parallel deep transcriptome and proteome analysis of zebrafish larvae. BMC Res. Notes 2013, 6, 428. [CrossRef]

30. Haggard, D.E.; Noyes, P.D.; Waters, K.M.; Tanguay, R.L. Transcriptomic and phenotypic profiling in developing zebrafish exposed to thyroid hormone receptor agonists. Reprod. Toxicol. 2018, 77, 80-93. [CrossRef]

31. Huang, X.; Agrawal, I.; Li, Z.; Zheng, W.; Lin, Q.; Gong, Z. Transcriptomic Analyses in Zebrafish Cancer Models for Global Gene Expression and Pathway Discovery. Adv. Exp. Med. Biol. 2016, 916, 147-168. [CrossRef]

32. Li, C.; Tan, X.F.; Lim, T.K.; Lin, Q.; Gong, Z. Comprehensive and quantitative proteomic analyses of zebrafish plasma reveals conserved protein profiles between genders and between zebrafish and human. Sci. Rep. 2016, 6, 24329. [CrossRef]

33. Tay, T.L.; Lin, Q.; Seow, T.K.; Tan, K.H.; Hew, C.L.; Gong, Z. Proteomic analysis of protein profiles during early development of the zebrafish, Danio rerio. Proteomics 2006, 6, 3176-3188. [CrossRef]

34. Link, V.; Shevchenko, A.; Heisenberg, C.P. Proteomics of early zebrafish embryos. BMC Dev. Biol. 2006, 6, 1-9. [CrossRef]

35. Lucitt, M.B.; Price, T.S.; Pizarro, A.; Wu, W.; Yocum, A.K.; Seiler, C.; Pack, M.A.; Blair, I.A.; Fitzgerald, G.A.; Grosser, T. Analysis of the zebrafish proteome during embryonic development. Mol. Cell Proteom. 2008, 7, 981-994. [CrossRef]

36. Vesterlund, L.; Jiao, H.; Unneberg, P.; Hovatta, O.; Kere, J. The zebrafish transcriptome during early development. BMC Dev. Biol. 2011, 11, 30. [CrossRef]

37. Forné, I.; Abián, J.; Cerdà, J. Fish proteome analysis: Model organisms and non-sequenced species. Proteomics 2010, 10, 858-872. [CrossRef]

38. Saxena, S.; Singh, S.K.; Lakshmi, M.G.; Meghah, V.; Sundaram, C.S.; Swamy, C.V.; Idris, M.M. Proteome profile of zebrafish kidney. J. Proteom. 2011, 74, 2937-2947. [CrossRef]

39. Smidak, R.; Aradska, J.; Kirchberger, S.; Distel, M.; Sialana, F.J.; Wackerlig, J.; Mechtcheriakova, D.; Lubec, G. A detailed proteomic profiling of plasma membrane from zebrafish brain. Proteom. Clin. Appl. 2016, 10, 1264-1268. [CrossRef]

40. Carneiro, M.; Gutiérrez-Praena, D.; Osório, H.; Vasconcelos, V.; Carvalho, A.P.; Campos, A. Proteomic analysis of anatoxina acute toxicity in zebrafish reveals gender specific responses and additional mechanisms of cell stress. Ecotoxicol. Environ. Saf. 2015, 120, 93-101. [CrossRef]

41. Biava, P.M.; Canaider, S.; Facchin, F.; Bianconi, E.; Ljungberg, L.; Rotilio, D.; Burigana, F.; Ventura, C. Stem cell differentiation stage factors from zebrafish embryo: A novel strategy to modulate the fate of normal and pathological human (stem) cells. Curr. Pharm. Biotechnol. 2015, 16, 782-792. [CrossRef] [PubMed]

42. Paradisi, M.; Alviano, F.; Pirondi, S.; Lanzoni, G.; Fernandez, M.; Lizzo, G.; Giardino, L.; Giuliani, A.; Costa, R.; Marchionni, C.; Bonsi, L.; Calza, L. Human mesenchymal stem cells produce bioactive neurotrophic factors: Source, individual variability and differentiation issues. Int. J. Immunopathol. Pharmacol. 2014, 27, 391-402. [CrossRef]

43. Bianchi, F.; Maioli, M.; Leonardi, E.; Olivi, E.; Pasquinelli, G.; Valente, S.; Mendez, A.J.; Ricordi, C.; Raffaini, M.; Tremolada, C.; Ventura, C. A new nonenzymatic method and device to obtain a fat tissue derivative highly enriched in pericyte-like elements by mild mechanical forces from human lipoaspirates. Cell Transplant. 2013, 22, 2063-2077. [CrossRef] [PubMed]

44. Li, X.; Song, Y.; Liu, D.; Zhao, J.; Xu, J.; Ren, J.; Hu, Y.; Wang, Z.; Hou, Y.; Zhao, G. MiR-495 promotes senescence of mesenchymal stem cells by targeting Bmi-1. Cell Physiol. Biochem. 2017, 42, 780-796. [CrossRef] [PubMed]

45. Molofsky, A.V.; Pardal, R.; Iwashita, T.; Park, I.K.; Clarke, M.F.; Morrison, S.J. Bmi-1 dependence distinguishes neural stem cell self-renewal from progenitor proliferation. Nature 2003, 425, 962-967. [CrossRef] [PubMed]

46. Rando, T.A. Stem cells, ageing and the quest for immortality. Nature 2006, 441, 1080-1086. [CrossRef] 
47. Da Silva, M.L.; Chagastelles, P.C.; Nardi, N.B. Mesenchymal stem cells reside in virtually all post-natal organs and tissues. J. Cell Sci. 2006, 119, 2204-2213. [CrossRef]

48. Neirinckx, V.; Coste, C.; Rogister, B.; Wislet-Gendebien, S. Concise review: Adult mesenchymal stem cells, adult neural crest stem cells, and therapy of neurological pathologies: A state of play. Stem Cells Transl. Med. 2013, 2, 284-296. [CrossRef]

49. Gronthos, S.; Mankani, M.; Brahim, J.; Robey, P.G.; Shi, S. Postnatal human dental pulp stem cells (DPSCs) in vitro and in vivo. Proc. Natl. Acad. Sci. USA 2000, 97, 13625-13630. [CrossRef] [PubMed]

50. Parolini, O.; Alviano, F.; Bagnara, G.P.; Bilic, G.; Bühring, H.J.; Evangelista, M.; Hennerbichler, S.; Liu, B.; Magatti, M.; Mao, N.; et al. Concise review: Isolation and characterization of cells from human term placenta: Outcome of the first international Workshop on Placenta Derived Stem Cells. Stem Cells 2008, 26, 300-311. [CrossRef]

51. La Rocca, G.; Lo Iacono, M.; Corsello, T.; Corrao, S.; Farina, F.; Anzalone, R. Human Wharton's jelly mesenchymal stem cells maintain the expression of key immunomodulatory molecules when subjected to osteogenic, adipogenic and chondrogenic differentiation in vitro: New perspectives for cellular therapy. Curr. Stem Cell Res. Ther. 2013, 8, 100-113. [CrossRef] [PubMed]

52. Laurent, L.C.; Ulitsky, I.; Slavin, I.; Tran, H.; Schork, A.; Morey, R.; Lynch, C.; Harness, J.V.; Lee, S.; Barrero, M.J.; et al. Dynamic changes in the copy number of pluripotency and cell proliferation genes in human ESCs and iPSCs during reprogramming and time in culture. Cell Stem Cell 2011, 8, 106-118. [CrossRef] [PubMed]

53. Chatgilialoglu, A.; Rossi, M.; Alviano, F.; Poggi, P.; Zannini, C.; Marchionni, C.; Ricci, F.; Tazzari, P.L.; Taglioli, V.; Calder, P.C.; Bonsi, L. Restored in vivo-like membrane lipidomics positively influence in vitro features of cultured mesenchymal stromal/stem cells derived from human placenta. Stem Cell Res. Ther. 2017, 8, 31. [CrossRef]

54. Hass, R.; Kasper, C.; Böhm, S.; Jacobs, R. Different populations and sources of human mesenchymal stem cells (MSC): A comparison of adult and neonatal tissue-derived MSC. Cell Comm Signal. 2011, 9, 12. [CrossRef] [PubMed]

55. Samsonraj, R.M.; Raghunath, M.; Nurcombe, V.; Hui, J.H.; van Wijnen, A.J.; Cool, S.M. Concise Review: Multifaceted Characterization of Human Mesenchymal Stem Cells for Use in Regenerative Medicine. Stem Cells Transl. Med. 2017, 6, 2173-2185. [CrossRef] [PubMed]

56. Xu, L.; Liu, Y.; Sun, Y.; Wang, B.; Xiong, Y.; Lin, W.; Wei, Q.; Wang, H.; He, W.; Wang, B.; Li, G. Tissue source determines the differentiation potentials of mesenchymal stem cells: A comparative study of human mesenchymal stem cells from bone marrow and adipose tissue. Stem Cell Res. Ther. 2017, 8, 275. [CrossRef] [PubMed]

57. Cong, Y.; Shay, J.W. Actions of human telomerase beyond telomeres. Cell Res. 2008, 18, 725-732. [CrossRef] [PubMed]

58. Bhattacharya, R.; Mustafi, S.B.; Street, M.; Dey, A.; Dwivedi, S.K. Bmi-1: At the crossroads of physiological and pathological biology. Genes Dis. 2015, 2, 225-239. [CrossRef]

59. Oh, J.; Lee, Y.D.; Wagers, A.J. Stem cell aging: Mechanisms, regulators and therapeutic opportunities. Nat. Med. 2014, 20, 870-880. [CrossRef]

60. Stampfer, M.R.; Garbe, J.; Nijjar, T.; Wigington, D.; Swisshelm, K.; Yaswen, P. Loss of p53 function accelerates acquisition of telomerase activity in indefinite lifespan human mammary epithelial cell lines. Oncogene 2003, 22, 5238-5251. [CrossRef]

61. Artandi, S.E.; Attardi, L.D. Pathways connecting telomeres and p53 in senescence, apoptosis, and cancer. Biochem. Biophys. Res. Commun. 2005, 331, 881-890. [CrossRef]

62. Shats, I.; Milyavsky, M.; Tang, X.; Stambolsky, P.; Erez, N.; Brosh, R.; Kogan, I.; Braunstein, I.; Tzukerman, M.; Ginsberg, D.; Rotter, V. p53-dependent down-regulation of telomerase is mediated by p21waf1. J. Biol. Chem. 2004, 279, 50976-50985. [CrossRef]

63. Liu, T.M.; Ng, W.M.; Tan, H.S.; Vinitha, D.; Yang, Z.; Fan, J.B.; Zou, Y.; Hui, J.H.; Lee, E.H.; Lim, B. Molecular basis of immortalization of human mesenchymal stem cells by combination of p53 knockdown and human telomerase reverse transcriptase overexpression. Stem Cells Dev. 2013, 22, 268-278. [CrossRef]

64. Sarin, K.Y.; Cheung, P.; Gilison, D.; Lee, E.; Tennen, R.I.; Wang, E.; Artandi, M.K.; Oro, A.E.; Artandi, S.E. Conditional telomerase induction causes proliferation of hair follicle stem cells. Nature 2005, 436, 1048-1052. [CrossRef] 
65. Choi, J.; Southworth, L.K.; Sarin, K.Y.; Venteicher, A.S.; Ma, W.; Chang, W.; Cheung, P.; Jun, S.; Artandi, M.K.; Shah, N.; Kim, S.K.; Artandi, S.E. TERT promotes epithelial proliferation through transcriptional control of a Myc- and Wnt-related developmental program. PLoS Genet. 2008, 4, e10. [CrossRef]

66. Bieback, K.; Brinkmann, I. Mesenchymal stromal cells from human perinatal tissues: From biology to cell therapy. World J. Stem Cells. 2010, 2, 81-92. [CrossRef]

67. Marchionni, C.; Bonsi, L.; Alviano, F.; Lanzoni, G.; Di Tullio, A.; Costa, R.; Montanari, M.; Tazzari, P.L.; Ricci, F.; Pasquinelli, G.; et al. Angiogenic potential of human dental pulp stromal (stem) cells. Int. J. Immunopathol. Pharmacol. 2009, 22, 699-706. [CrossRef]

68. Pierdomenico, L.; Bonsi, L.; Calvitti, M.; Rondelli, D.; Arpinati, M.; Chirumbolo, G.; Becchetti, E.; Marchionni, C.; Alviano, F.; Fossati, V.; et al. Multipotent mesenchymal stem cells with immunosuppressive activity can be easily isolated from dental pulp. Transplantation 2005, 80, 836-842. [CrossRef]

69. La Rocca, G.; Anzalone, R.; Corrao, S.; Magno, F.; Loria, T.; Lo Iacono, M.; Di Stefano, A.; Giannuzzi, P.; Marasà, L.; Cappello, F.; et al. Isolation and characterization of Oct-4+/HLA-G+ mesenchymal stem cells from human umbilical cord matrix: Differentiation potential and detection of new markers. Histochem. Cell Biol. 2009, 131, 267-282. [CrossRef]

70. Livraghi, T.; Meloni, F.; Frosi, A.; Lazzaroni, S.; Bizzarri, T.M.; Frati, L.; Biava, P.M. Treatment with stem cell differentiation stage factors of intermediate-advanced hepatocellular carcinoma: An open randomized clinical trial. Oncol. Res. 2005, 15, 399-408. [CrossRef]

71. Rinaldi, S.; Maioli, M.; Pigliaru, G.; Castagna, A.; Santaniello, S.; Basoli, V.; Fontani, V.; Ventura, C. Stem cell senescence. Effects of REAC technology on telomerase-independent and telomerase-dependent pathways. Sci. Rep. 2014, 4, 6373. [CrossRef]

72. Facchin, F.; Bianconi, E.; Romano, M.; Impellizzeri, A.; Alviano, F.; Maioli, M.; Canaider, S.; Ventura, C. Comparison of Oxidative Stress Effects on Senescence Patterning of Human Adult and Perinatal Tissue-Derived Stem Cells in Short and Long-term Cultures. Int. J. Med. Sci. 2018, 15, 1486-1501. [CrossRef]

73. Rossi, M.; Alviano, F.; Ricci, F.; Vignoli, F.; Marchionni, C.; Valente, S.; Zannini, C.; Tazzari, P.L.; Vignoli, M.; Bartoletti, E.; Bonsi, L. In vitro multilineage potential and immunomodulatory properties of adipose derived stromal/stem cells obtained from nanofat lipoaspirates. CellR4 2016, 4, e2212.

74. Casadei, R.; Piovesan, A.; Vitale, L.; Facchin, F.; Pelleri, M.C.; Canaider, S.; Bianconi, E.; Frabetti, F.; Strippoli, P. Genome-scale analysis of human mRNA 5' coding sequences based on expressed sequence tag (EST) database. Genomics 2012, 100, 125-130. [CrossRef] [PubMed]

75. Facchin, F.; Vitale, L.; Bianconi, E.; Piva, F.; Frabetti, F.; Strippoli, P.; Casadei, R.; Pelleri, M.C.; Piovesan, A.; Canaider, S. Complexity of bidirectional transcription and alternative splicing at human RCAN3 locus. PLoS ONE 2011, 6, e24508. [CrossRef]

76. Beraudi, A.; Bianconi, E.; Catalani, S.; Canaider, S.; De Pasquale, D.; Apostoli, P.; Bordini, B.; Stea, S.; Toni, A.; Facchin, F. In vivo response of heme-oxygenase-1 to metal ions released from metal-on-metal hip prostheses. Mol. Med. Rep. 2016, 14, 474-480. [CrossRef] [PubMed]

77. Bustin, S.A.; Benes, V.; Garson, J.A.; Hellemans, J.; Huggett, J.; Kubista, M.; Mueller, R.; Nolan, T.; Pfaffl, M.W.; Shipley, G.L.; Vandesompele, J.; Wittwer, C.T. The MIQE guidelines: Minimum information for publication of quantitative real-time PCR experiments. Clin. Chem. 2009, 55, 611-622. [CrossRef]

(C) 2019 by the authors. Licensee MDPI, Basel, Switzerland. This article is an open access article distributed under the terms and conditions of the Creative Commons Attribution (CC BY) license (http://creativecommons.org/licenses/by/4.0/). 